\title{
Platelet Derived Growth Factor Receptor $\beta$ (PDGFR $\beta$ ) is a Host Receptor for the human malaria parasite adhesin TRAP
}

\author{
Ryan W. J. Steel ${ }^{1 * \&}$, Vladimir Vigdorovich ${ }^{1 *}$, Nicholas Dambrauskas ${ }^{1}$, \\ Brandon K. Wilder ${ }^{1 \S}$, Silvia A. Arredondo ${ }^{1}$, Debashree Goswami ${ }^{1}$, Sudhir Kumar ${ }^{1}$, \\ Sara Carbonetti ${ }^{1}$, Kristian E. Swearingen ${ }^{2}$, Thao Nguyen ${ }^{1}$, Will Betz ${ }^{1}$, Nelly Camargo ${ }^{1}$, \\ Bridget S. Fisher ${ }^{1}$, Jo Soden ${ }^{3}$, Helen Thomas ${ }^{3}$, Jim Freeth ${ }^{3}$, Robert L. Moritz ${ }^{2}$, \\ D. Noah Sather ${ }^{1,4,5 \#}$, Stefan H.I. Kappe $e^{1,4,5 \#}$
}

${ }^{1}$ Seattle Children's Research Institute, Seattle, WA, USA

2 Institute for Systems Biology, Seattle, WA, USA

${ }^{3}$ Retrogenix Ltd, Chinley, High Peak, SK23 6FJ, United Kingdom

${ }^{4}$ Department of Pediatrics, University of Washington, Seattle, WA, USA

${ }^{5}$ Department of Global Health, University of Washington, Seattle, WA, USA

* Equal contribution

\& Present address: Infectious Disease and Immune Defence Division, The Walter and Eliza Hall Institute of Medical Research, Parkville 3052, VIC, Australia

$\S$ Present address: Vaccine and Gene Therapy Institute, Oregon Health \& Science University, Beaverton, OR 97006

\#To whom correspondence should be addressed: Stefan Kappe stefan.kappe@seattlechildrens.org; D. Noah Sather noah.sather@seattlechildrens.org

Running title: PDGFRß interacts with human malaria parasite TRAP

Keywords: human, plasmodium, adhesin, host-pathogen interaction, protein-protein interaction, Plasmodium falciparum, Plasmodium vivax, TRAP, sporozoite, platelet derived growth factor receptor beta 


\section{Abstract}

Following their inoculation by the bite of an infected Anopheles mosquito, the malaria parasite sporozoite forms travel from the bite site in the skin into the bloodstream, which transports them to the liver. The thrombospondin-related anonymous protein (TRAP) is a type 1 transmembrane protein that is released from secretory organelles and relocalized on the sporozoite plasma membrane. TRAP is required for sporozoite motility and host infection, and its extracellular portion contains adhesive domains that are predicted to engage host receptors. Here, we identified the human platelet-derived growth factor receptor $\beta$ (hPDGFR $\beta$ ) as one such protein receptor. Deletion mutants showed that the von Willebrand factor type A and thrombospondin repeat domains of TRAP are both required for optimal binding to hPDGFRß-expressing cells. We also demonstrate that this interaction is conserved in the human-infective parasite Plasmodium vivax, but not the rodent-infective parasite Plasmodium yoelii. We observed expression of hPDGFR $\beta$ mainly in cells associated with the vasculature suggesting that TRAP:hPDGFR interaction may play a role in the recognition of blood vessels by invading sporozoites. 


\section{Introduction}

There were more than 400,000 deaths and 228 million estimated new clinical cases of malaria in 2019, the vast majority of which were caused by Plasmodium falciparum and $P$. vivax (1). Malaria infection begins when $\leq 100$ sporozoites are deposited into the skin by the bite of a female Anopheles mosquito (2). While in skin, sporozoites search for blood vessels using unknown molecular interactions, and then invade the vasculature, through which they are transported to the liver. Here, sporozoites extravasate by traversing liver sinusoidal cells and Kupffer cells, and subsequently enter the liver parenchyma $(3,4)$. In the liver, each sporozoite traverses several hepatocytes before ultimately selecting one suitable for infection, within which it transforms and grows as liver-stage parasite, ultimately differentiating into tens of thousands of exoerythrocytic merozoites. Upon egress from the liver, these merozoites go on to infect red blood cells. The ensuing erythrocytic infection cycle rapidly increases the parasite load and is responsible for all clinical malaria symptoms, as well as for giving rise to mosquito infectious stages ready for uptake by a new mosquito vector (5-9). Thus, the sporozoite stage is considered an attractive target for intervention, since preventing a relatively small number of parasites from reaching the liver promises to prevent both disease and onwards transmission of the parasite.

Parasite adhesion proteins enabling sporozoite motility, tissue traversal and infection are released from a set of apical organelles, the micronemes and rhoptries (10). An important sporozoite micronemal protein called thrombospondin-related anonymous protein (TRAP), is relocalized from the micronemes to the sporozoite 
surface and mediates motility and infection via interaction of its cytoplasmic domain with the actin/myosin motor (11). The extracellular portion of TRAP contains two adhesive domains, a von Willebrand factor A (VWA)-like domain with a metal ion-dependent adhesion site (MIDAS), and a thrombospondin repeat domain (TSR domain). TSR and VWA domains in other organisms are broadly involved in receptor binding, cell-cell recognition and cell adhesion, suggesting a similar role for TRAP in binding host receptors. The TSR domain of TRAP has been shown to bind to heparan sulfate proteoglycans (HSPGs) on the surface of hepatocytes (12). Proteolytic processing of TRAP at a rhomboid protease site positioned between the repeats and the transmembrane domain (Fig. 1A) has been shown to be important for sporozoite motility (13).

TRAP localization in sporozoites is a dynamically controlled process. A small amount of TRAP is released apically from micronemes and subsequently translocated rearward on the sporozoite surface during gliding, acting as an essential link between the sporozoite actin/myosin motor and extracellular substrates (13-15). During hepatocyte infection, TRAP becomes largely surface-exposed at the anterior tip of the sporozoite along with other invasion-related proteins, where it is presumably involved in the engagement of host cell receptors (16). This binding to host receptors has been proposed to follow a 'dual binding system' model in which the VWA and TSR domains of TRAP coordinate host receptor engagement to allow efficient host infection (17). Mutations in either of these domains reduce sporozoite infectivity while their simultaneous mutation or deletion renders sporozoites non-motile and non-infectious 
$(17,18)$. Crystal structures suggest that TRAP undergoes conformational changes when divalent cations bind to its MIDAS site (19).

The critical role of TRAP during host infection makes it an attractive vaccine candidate, although efforts to generate protective antibody responses against TRAP have achieved only limited success to date (20-24). Thus, a better understanding of the specific host-receptor interactions of TRAP during infection would aid ongoing vaccine development by directing rational vaccine design efforts.

Here we expressed the ectodomain of $P$. falciparum TRAP (PfTRAP) and screened for interaction with $>4300$ individually overexpressed human cell surface receptors. We found that PfTRAP interacts with human platelet-derived growth factor receptor $\beta$ (hPDGFR $\beta$ ) and further investigated this interaction using HEK293F cells overexpressing this receptor. Binding of PfTRAP to hPDGFR $\beta$ was inhibited by monoclonal antibodies directed against PfTRAP or hPDGFRß. We further studied what domains of PFTRAP were required for this interaction, and whether the engagement of PDGFR $\beta$ by TRAP is conserved in other Plasmodium species.

\section{$\underline{\text { Results }}$}

\section{Recombinant $P$. falciparum TRAP interacts with human PDGFR $\beta$}

To identify host receptors for PfTRAP, we expressed its full ectodomain (Table 1, Fig. 1A) in HEK293F cells and purified the soluble secreted protein (Suppl. Fig. 1B). Using this protein, we undertook a screen of $>4300$ unique human plasma membrane 
proteins using the Retrogenix® Cell Microarray platform. In this screen, individual constructs encoding membrane proteins were reverse-transfected into HEK293 cells resulting in an array of populations overexpressing different targets. These fixed arrays were then interrogated using fluorescent complexes containing the PfTRAP ectodomain in search of human receptors that demonstrated reproducible binding to PfTRAP. This screen revealed hPDGFR $\beta$ as a PfTRAP-interacting protein (Suppl. Fig. 2). We subsequently verified this interaction using a flow-cytometry-based binding assay, in which HEK293F cells overexpressing hPDGFR $\beta$ were stained with fluorescent complexes containing the PfTRAP ectodomain oligomerized around a phycoerythrin-streptavidin core (Fig. 1B).

In order to assess the expression of hPDGFR in tissues most relevant for sporozoite infection, we undertook an immunohistochemical analysis of normal human skin and liver using an antibody specific for hPDGFR expression was observed in pericytes that undergird the basement membrane of blood vessels (Fig. 2A). To a lesser degree, hPDGFR $\beta$ was also expressed in the basal cell layer of the epidermis. In the liver, more diffuse, low levels of hPDGFR $\beta$ were observed in proximity to major vessels but not in association with liver sinusoids (Fig. 2B). 


\section{Optimal engagement of hPDGFR $\beta$ by $P$. falciparum TRAP requires the VWA and}

\section{TSR domains and is independent from the mechanism of binding to}

\section{av-containing integrin}

We used our flow-cytometry-based binding assay to further investigate the interaction between hPDGFR $\beta$ and TRAP (the full gating strategy is shown in Suppl.

Fig. 3). In addition to the full-length ectodomain, we expressed and purified five deletion constructs of PfTRAP (Table 1; Suppl. Fig. 1B), as well as the homodimeric form of human platelet derived growth factor B (hPDGF-BB), a known ligand of hPDGFR $\beta$, to be used as a positive control. All purified recombinant proteins were biotinylated and oligomerized using a phycoerythrin-streptavidin conjugate to form a fluorescent staining reagent that was then tested across a 3-log concentration range for binding to HEK293F cells overexpressing hPDGFR $\beta$. Untransfected cells present within each experiment (and trackable due to the lack of GFP signal, which indicated the presence of the fusion hPDGFR $\beta$ protein), were used to calculate the geometric mean fluorescence intensity (gMFI) ratio with respect to the cells expressing hPDGFRß-GFP fusion (referred to as gMFI Index).

Full-length PfTRAP ectodomain bound in a concentration-dependent manner to hPDGFR $\beta$-expressing cells (Fig. 1C). This binding was enhanced $(p<0.01$; Suppl. Fig. 4) for the VWA+TSR fragment (Fig. 1D). The VWA fragment without the TSR domain bound only modestly (Fig. 1E), while the TSR, alone or in combination with the repeats, or the repeats alone, did not bind to HEK293F cells overexpressing hPDGFRß (Figs. $1 F, G, H)$. 
We next used monoclonal antibodies (mAbs) directed against PfTRAP and hPDGFR $\beta$ to further evaluate this interaction. Antibodies that bind the PfTRAP VWA domain reduced the binding of both the full-length ectodomain and the VWA+TSR fragment of PfTRAP by approximately $80 \%$ and $90 \%$, respectively, but these mAbs did not affect binding of the known ligand hPDGF-BB to hPDGFRß (Fig. 3A). We also employed mAb 2C5, which binds to mouse and human PDGFRß (Suppl. Fig. 5) and blocks activation of these receptors by their natural ligand PDGF-BB in vitro and in vivo (25). MAb 2C5 significantly reduced the binding of full-length ectodomain and the WWA+TSR fragment, and that of the known ligand, hPDGF-BB, to HEK293F cells overexpressing hPDGFRß (Fig. 3B). The blocking activity of the antibodies against either partner indicates the specificity of the interaction between hPDGFR $\beta$ and PfTRAP on the cell surface.

Despite having shown binding of PFTRAP to cell-associated hPDGFRß in our cell-based screen, we were unable to detect binding of PfTRAP to the recombinant soluble form of hPDGFRß in vitro (Suppl. Fig. 6A), even when measured at high concentration of analyte or in the presence of excess divalent cations (Suppl. Fig. 6B).

In a recent report, the ectodomain of $P$. falciparum TRAP was shown to bind av-integrin in a cell-based assay. The mechanism required divalent cations, presumably coordinated by the MIDAS motif of the TRAP VWA domain, and an integrin-binding RGD motif following the TSR domain (26). We therefore sought to distinguish av-integrin-mediated interactions from those we found for hPDGFRß. The HEK293F cells used in our assay endogenously express av-integrin (Suppl. Fig. 7). Therefore, we 
measured PfTRAP binding to untransfected cells under conditions previously shown to inhibit binding to av-integrin. PfTRAP ectodomain, indeed, bound to untransfected cells and this binding was disrupted in the presence of the divalent cation chelator EDTA as well as by anti-av-integrin antibodies (Fig. 4A, B), in agreement with previous findings (26). Furthermore, our PfTRAP VWA+TSR fragment lacks the RGD-containing repeat region, and did not bind significantly to untransfected cells (Fig. 4B). This indicated that the binding to untransfected cells potentially was due to the interaction with the av-integrin. We next tested the effect of EDTA and anti-av-integrin antibodies on PfTRAP binding to cells transfected with hPDGFRß. Both the full ectodomain and the VWA+TSR constructs of PfTRAP showed strong binding that was not affected by EDTA or anti-av-integrin antibodies (Fig. 4C, D), indicating that the binding measured in hPDGFR $\beta$-transfected cells was not due to binding endogenous av-integrin, but was specific to hPDGFR $\beta$.

Collectively these data show that optimal binding of PfTRAP to hPDGFR $\beta$ is mediated by the VWA and TSR domains acting together. We also show that this interaction can be disrupted using host- and parasite-directed antibodies and demonstrate that the binding of PfTRAP to hPDGFR $\beta$-expressing cells is distinguishable from the recently discovered interaction with av-integrins (26).

We next set out to test whether the TRAP:PDGFR interaction is important for sporozoite infection of the mammalian host. To this end, we tested passive transfer of mPDGFR blocking mAb 2C5 (which also blocks mouse mPDGFR $\beta$ ) into mice, followed by sporozoite challenge via mosquito bite using the rodent malaria parasite $P$. yoelii 
(Suppl. Figs. 5C, 5D). Interestingly, mPDGFR $\beta$ blockade with mAb $2 \mathrm{C} 5$ did not have a significant effect on sporozoite infection of mice when compared to control. This result precipitated a further investigation into whether the TRAP:PDGFR $\beta$ interaction is conserved among Plasmodium species.

\section{Engagement of PDGFR $\beta$ is conserved across human-infective Plasmodium} species but not in a rodent-infective Plasmodium species.

We produced a recombinant ectodomain fragment for the human-infective malaria parasite $P$. vivax (PVTRAP), as well as full ECD and $\mathrm{N}$-terminal adhesive domains (VWA+TSR) fragments for the rodent infective malaria parasite $P$. yoelii (PyTRAP) (Table 1; Suppl. Figs. 1C, 1D) and tested them for binding to cells overexpressing PDGFR $\beta$ of mouse (mPDGFR $\beta$ ) and human (hPDGFR $\beta$ ) origin. Binding of PVTRAP to hPDGFR $\beta$, was seen in a concentration-dependent manner that was not significantly different from the binding of PfTRAP (Fig. 5A). We, however, observed no binding of either PyTRAP ectodomain or VWA+TSR to mPDGFR $\beta$ (Fig. 5B). This might explain why we observed that blocking the interaction in a rodent malaria infection model had no discernable effect on sporozoite infection (Suppl. Figs. 5C and 5D).

Finally, we assessed the cross-interaction of PyTRAP with hPDGFR $\beta$, and PfTRAP with mPDGFR $\beta$. The PfTRAP fragment bound significantly to mPDGFR $\beta$, albeit only at approximately $50 \%$ of the level of binding to hPDGFR $\beta$ (Fig. $5 \mathrm{C}$ ). No binding of PyTRAP to either mPDGFR $\beta$ or hPDGFR $\beta$ was observed. Both human and mouse 
PDGFR $\beta$ bound the human PDGF-BB ligand to a similar extent (Fig. 5D), ruling out gross discrepancies in protein localization or expression levels affecting these results.

\section{Discussion}

Over the last decade, numerous Plasmodium proteins have been identified that play a role in the sporozoites' journey from the site of deposition in the skin to their destination in the liver and their ultimate infection of host hepatocytes (27). Furthermore, host hepatocyte surface proteins CD81, SR-B1 and EphA2 have been described as critical factors for infection of hepatocytes (28-30). Yet, linking host receptors to sporozoite ligands has been exceedingly difficult, and sporozoite protein/host cell protein interaction pairs that might play a role in host infection remain virtually unknown. We have herein identified PDGFR $\beta$ as a novel host receptor for the essential sporozoite adhesin TRAP by screening $>4300$ human plasma membrane proteins. The PDGFRß:TRAP interaction can be blocked with mAbs to either the parasite protein or the host receptor, requires both TRAP VWA and TSR domains for efficient binding, and is independent of the TRAP MIDAS and RGD motifs. Intriguingly, the PDGFR $\beta$ interaction with TRAP is conserved among the major human-infective $P$. falciparum and $P$. vivax parasites but not for the rodent-infective parasite $P$. yoelii.

Binding of recombinant PfTRAP to hPDGFR $\beta$ was detectable in our cell-based assay in a concentration-dependent manner. However, we were unable to detect binding of recombinant TRAP to the purified soluble form of PDFGR $\beta$, despite detecting 
a robust interaction with its known ligand PDGF-BB. It is possible that the conformation of the membrane-anchored PDGFR $\beta$ differs from that of its soluble counterpart, or that TRAP interaction requires presence of additional proteins associated with PDGFRß.

Our findings complement the recent study by Dundas and colleagues (26) in which avß3 integrin was identified as a host receptor for TRAP. It is likely that this interaction was not detected in our human surface protein screen because only individual proteins were overexpressed. We have independently validated the binding of PfTRAP to av-containing integrins, which have basal expression in our cell-based system. However, we have shown that binding to hPDGFR $\beta$ was distinct as indicated by our findings that (i) binding to hPDGFR $\beta$ did not require the RGD motif containing repeat region, (ii) binding was insensitive to anti-av antibodies and (iii) unlike the interaction with av-containing integrins (26), binding did not require divalent cations. Furthermore, the interaction with hPDGFR $\beta$ was conserved for TRAP of $P$. falciparum and $P$. vivax. In contrast, the interaction between integrin $\alpha v \beta 3$ and the TRAP of $P$. vivax had not been observed by Dundas et al. (26). Thus, it is highly likely that the interactions of TRAP with $\alpha \mathrm{v} \beta 3$ and PDGFR $\beta$ are distinct and might serve different biological functions during the infection process.

In order to directly establish the potential importance of the TRAP:PDGFR interaction, we initially attempted to block the interaction in vivo and measure the effect on sporozoite transmission success, using the $P$. yoelii mouse malaria model. Interestingly, however, $P$. yoelii TRAP failed to show significant binding to hPDGFR $\beta$ or mPDGFR $($ Fig. 5C). Therefore, it is probable that the interaction between TRAP and 
PDGFR $\beta$ is not conserved in $P$. yoelii, and this will not be an adequate model to study the biology of TRAP:PDGFR $\beta$ interaction. Thus, our findings are adding to the emerging picture of differences in the conservation of host receptor engagement by orthologous effector proteins between human-infective and rodent-infective Plasmodium species $(26,31)$.

PDGFR plays a major role in angiogenesis and maintenance of vascular integrity, and was shown to be expressed by lymphatic endothelial cells as well as pericytes supporting endothelial cells during development (32-34). Additionally, PDGF receptors have long been recognized to play an important role in cutaneous wound healing (35). Consistent with these published vascular expression patterns, we detected PDGFR expression in a perivascular distribution in human skin. Expression was strong in pericytes that undergird the vascular endothelium, which in turn was unequivocally identifiable with the endothelial cell marker CD31. Likewise, liver PDGFRß expression was restricted to vasculature. Thus, it is possible that the TRAP:PDGFR $\beta$ interaction may have a role in mediating sporozoite recognition of the vasculature. However, our findings indicate that TRAP:PDGFR $\beta$ interaction is not conserved among the different Plasmodium species, and that further functional studies of this interaction must be undertaken in model systems that recapitulate the human vascular compartment.

Combined with recent studies, our findings provide a more complete understanding of the potential molecular interactions of TRAP with host receptors. While the biological consequences of the TRAP:PDGFR interaction remain to be fully 
bioRxiv preprint doi: https://doi.org/10.1101/2020.05.12.091488; this version posted May 13, 2020. The copyright holder for this preprint (which

was not certified by peer review) is the author/funder, who has granted bioRxiv a license to display the preprint in perpetuity. It is made available under aCC-BY 4.0 International license.

deciphered, our work provides a novel molecular interaction lead that could mediate the initial infection of the mammalian host. 


\section{Experimental procedures}

\section{Recombinant Protein Production}

Production of recombinant proteins in suspension HEK293F cells cultures was performed, as previously described $(28,36,37)$. Briefly, each expression construct contained codon-optimized sequences encoding a tissue plasminogen activator signal peptide (38), the full extracellular domain or subdomains from P. yoelii TRAP (PyTRAP) (PlasmoDB:PYYM_1351500), P. falciparum TRAP (PfTRAP) (PlasmoDB:

PF3D7_1335900) or P. vivax TRAP (PvTRAP) (Table 1), and a C-terminal $\mathrm{His}_{8}$ tag followed by an AviTag (39) cloned into the pcDNA-3.4 vector backbone (Thermo Fisher, Waltham, MA, USA). Constructs encoding tagged human PDGF-B (residues 82-190) (purified as homodimeric hPGDF-BB), and the tagged ectodomain of hPDGFR $\beta$ (residues 33-532) were similarly created.

The PVTRAP sequence was based on that observed by proteomic analysis of a Thai $P$. vivax salivary gland sporozoite sample bearing the VK247 haplotype of CSP (40). Protein sequence polymorphisms in the field isolate were identified by augmenting the $P$. vivax Sal-1 genome (41) used for the protein sequence database search with the P. vivax P01 genome (42) as well as sequence polymorphisms observed in RNA-seq analyses of 19 different Thai field isolates (43). Additionally, $S \rightarrow A$ and $T \rightarrow A$ substitutions were made in $\mathrm{NX}[\mathrm{S} / \mathrm{T}]$ motifs to prevent $\mathrm{N}$-linked glycosylation, as this modification has not been shown to occur in Plasmodium $(44,45)$ and is absent from TRAP in vivo (46). 
Constructs were introduced into HEK293F cells by high-density transfection with PEI MAX 40K (Polysciences, Inc., Warrington, PA, USA) $(47,48)$, and culture supernatants containing the recombinant proteins were harvested after 5 days. Proteins were purified by $\mathrm{Ni}^{2+}$-affinity chromatography followed by size-exclusion chromatography. Subsequently, a BirA biotin-protein ligase kit (Avidity, LLC; Aurora ,CO, USA) was used to biotinylate protein samples, as previously described (37). Biotinylated proteins were re-purified by size-exclusion chromatography to remove free biotin, and multimerized using streptavidin-phycoerythrin (ProZyme) by mixing 1 molar-equivalent of streptavidin-phycoerythrin with 4 molar-equivalents of biotinylated protein.

\section{Retrogenix ${ }^{\circledR}$ Cell Microarray Screen}

Screening for PfTRAP binding proteins was performed using the Retrogenix Cell Microarray technology. Initially 4336 expression vectors, each encoding a unique human plasma membrane protein and the ZsGreen1 fluorescent protein, were pre-spotted on glass slides. Human HEK293 cells were grown over the arrays and reverse-transfected, resulting in the over-expression of each membrane protein and ZsGreen1. Slides were then incubated with QDot ITK Carboxyl Quantum Dots, 585 nM (Life Technologies cat \# Q21311MP) which were pre-coupled with Ni-NTA and coated with His-tagged PfTRAP, giving a final PfTRAP concentration of $100 \mathrm{nM}$. PfTRAP binding proteins were identified by fluorescence imaging (at $\sim 500 \mathrm{~nm}$ wavelength for ZsGreen1 and at $\sim 585 \mathrm{~nm}$ for QDots) analysed using ImageQuant software (GE). For 
confirmation and specificity testing, expression vectors encoding the PfTRAP binding proteins were re-spotted on new slides, and HEK293 cells were reverse-transfected. Slides were then treated with the same Ni-NTA-coupled QDots coated with His-tagged PfTRAP as before, or with His-tagged PDL1 (each at $100 \mathrm{nM}$ final concentration), or with no ligand conjugated. Interactions were analysed by fluorescence imaging.

\section{Protein binding measurements}

Protein interactions were analyzed using biolayer interferometry on an Octet QKe instrument (ForteBio). Streptavidin (SA) biosensors were used to immobilize biotinylated recombinant ligand molecules followed by equilibration in 10x Kinetics Buffer (PBS + $0.1 \%$ BSA, $0.02 \%$ Tween-20 and $0.05 \%$ sodium azide), detection of association of recombinant analyte proteins diluted in the same buffer, and detection of dissociation in analyte-free 10x Kinetics Buffer.

Experiments requiring the use of salts of divalent metals required phosphate to be substituted with HEPES (since phosphate formed poorly soluble salts with several of the metal ions tested). In those cases, we used HBS-P (20 mM HEPES, pH 7, $150 \mathrm{mM}$ $\mathrm{NaCl}, 0.1 \% \mathrm{BSA}, 0.02 \%$ Tween-20) as the base buffer.

\section{Flow Cytometry Binding Assays}

To further analyze TRAP binding, biotinylated recombinant TRAP proteins (Table 1) were oligomerized around a streptavidin-conjugated Phycoerythrin (PE) (PJRS2, Prozyme) creating TRAP-PE staining complexes. Sequence verified human (clone 
IMAGE:5309813) and mouse (clone IMAGE:30060666) cDNAs for PDGFRß were obtained from the Dharmacon Mammalian Gene Collection (GE Healthcare) for creation of surface-expressed GFP fusion receptor constructs. The open reading frame, including the transmembrane region and a short intracellular linker, were cloned into a pcDNA3.4 expression vector (Thermo Fisher) in which the intracellular tyrosine kinase domain of the receptor was replaced with Cycle3 GFP. Approximately $3 \times 10^{6}$ HEK293F cells were transfected with one of these constructs using 293fectin Transfection Reagent (Thermo Fisher) or 293-Free (EMD Millipore), according to the manufacturer's instructions (Thermo Fisher) and maintained in FreeStyle 293 serum-free medium (Thermo Fisher). Two days after transfection approximately $5 \times 10^{5}$ cells were transferred to 96 -well plates, pelleted at $500 \times \mathrm{g}$ for 3 minutes, then resuspended and incubated with various concentrations of protein complexes in FACS buffer (PBS $+2 \%$ FBS) for 30 minutes on ice. Cells were then washed three times with FACS buffer before analysis without fixation on an LSR II Flow Cytometer (Becton Dickinson) using FlowJo (TreeStar). Specificity for binding to the transfected receptor was measured by the geometric mean fluorescent intensity (gMFI) of PE on transfected $\left(\mathrm{GFP}^{+}\right)$cells normalized to the untransfected $\left(\mathrm{GFP}^{-}\right)$cells in the same well, termed the gMFI Index. Experiments with the known ligand for PDGFR $\beta$, a dimer of the human Platelet-Derived Growth Factor-B (hPDGF-BB), and mock transfected cells were included as controls in the assays. Experiments testing the role of divalent metals in binding were done in presence of $10 \mathrm{mM}$ EDTA. Blocking of the integrin av binding was performed using the mouse monoclonal 272-17E6 antibody (Abcam). 


\section{Recombinant antibody production}

For PfTRAP blocking experiments monoclonal antibodies recognizing PfTRAP were produced as previously described (37). Briefly, BALB/cJ mice were immunized intramuscularly three times, three weeks apart, with $20 \mu \mathrm{g}$ of PfTRAP full ectodomain formulated in Adjuplex (Sigma Aldrich). Two weeks following the final immunization, spleens from PfTRAP immunized mice were harvested, dissociated, and antigen-specific B cells sorted by FACS into 96-well plates for subsequent culture. Sorted cells were stimulated to secrete antibody and supernatants screened for antigen-binding antibodies by ELISA. Antibody sequences encoding the variable regions of heavy and light chains were rescued from the positive wells using RT-PCR and fused to constant-region encoding DNA fragments to build expression constructs.

For PDGFR $\beta$ receptor blocking experiments, a previously published monoclonal antibody identified from a phage display library (clone 2C5) and capable of neutralizing both mouse and human PDGFR $\beta$ (25) was expressed as a recombinant human IgG1. Briefly, the variable heavy- and light-chain sequences were obtained from Creative Biolabs (NY, USA) and cloned directly into antibody expression vectors containing constant-region sequences.

Antibodies were expressed using the HEK293F culture, as described above for protein production. Following 5 days in culture, supernatants were cleared by centrifugation, supplemented with $\mathrm{NaCl}(+350 \mathrm{mM}$, final concentration), and applied over Protein G Sepharose Fast Flow (GE Lifesciences). Protein was eluted using $0.1 \mathrm{M}$ 
glycine ( $\mathrm{pH} 2.7)$, and the $\mathrm{pH}$ was immediately neutralized using $1 \mathrm{M}$ dibasic sodium phosphate.

\section{Immunohistochemistry}

Localization of PDGFR $\beta$ in formalin-fixed paraffin-embedded normal human skin and liver sections (Amsbio, MA, USA) was performed using a EnVision G2 Doublestain System, Rabbit/Mouse (Agilent). This staining procedure can be used for sequential double staining of two different antigens with primary antibodies raised in the same species by incorporating a blocking step between the first and second antibody incubations. Briefly, sections were deparaffinized and rehydrated by standard methods, antigens retrieved by immersion in boiling $10 \mathrm{mM}$ sodium citrate $(\mathrm{pH}$ 6.0) for 10 minutes, and endogenous peroxidase activity quenched according to the manufacturer's instructions. Sections were then blocked and permeabilized in Protein Block Serum-Free (Agilent) for 20 min at room temperature before incubation with primary rabbit monoclonal antibody against PDGFR (Abcam; clone Y92). Sections were washed twice in TBS-Tween 0.05\% (20 mM Tris pH 8, $150 \mathrm{mM} \mathrm{NaCl}, 0.05 \%$ Tween-20) for $5 \mathrm{~min}$. Polymer/HRP (Agilent) was added to the sections and sections were incubated for $30 \mathrm{~min}$ at room temperature in the dark. Sections were washed twice with TBS-Tween $0.05 \%$ for 5 min each. DAB chromogen (diluted 1 drop every $1 \mathrm{~mL}$ DAB buffer) was added to the sections, and slides were incubated in the dark for 20 min. Sections were washed with distilled water to stop the reaction. For staining of vasculature, sections were stained with the rabbit monoclonal antibody against the 
endothelial marker CD31 (Abcam; clone EPR3094). Sections were washed with TBS-Tween $0.05 \%$ for $5 \mathrm{~min}$ and rabbit/mouse link (Agilent) was added to slides and incubated for $15 \mathrm{~min}$ at room temperature in the dark. Sections were washed twice in TBS-Tween $0.05 \%$ for $5 \mathrm{~min}$ and polymer-AP was added. Sections were incubated for 30 mins at room temperature in the dark followed by two washes with TBS-Tween 0.05\% 5 min. To visualize CD31, Vector Blue substrate (Vector Laboratories) was prepared according to manufacturer's instructions and added to the sections for 20 mins. Reaction was stopped with water. PDGFR $\beta$ straining (brown) and CD31 staining (blue) were visualized and imaged using the Keyence BZ-X710 microscope.

\section{Mosquito Rearing and Sporozoite Production}

Anopheles stephensi mosquitoes were reared according to standard protocols and adult females were infected with Plasmodium parasites 3-7 days after their emergence. For $P$. yoelii sporozoite production, female 6-8-week-old Swiss Webster mice were injected with blood stage 17XNL parasites constitutively expressing GFP/Luciferase (PyGLuc) (49) to begin the growth cycle, and infected mice were used to feed adult female Anopheles stephensi mosquitoes after gametocyte exflagellation was observed. Blood-fed mosquitoes were then maintained according to standard protocols before their use in animal challenge studies. 


\section{mAb 2C5 passive transfer protection studies}

All experiments involving animals were performed under protocols approved by the Institutional Animal Care and Use Committee at the Seattle Children's Research Institute. Mice received two, $800-\mu g$ injections of $\mathrm{mAb} 2 \mathrm{C5}$ or isotype control human IgG before infectious mosquito bite challenge. The first injection was i.p. 18 hours before challenge to allow distribution of the antibody throughout the tissues, while the second was i.v. 1 hour before to ensure a high serum antibody concentration at the time of challenge. Host directed antibodies against CD81 have been shown to prevent malaria infection with a single dose of $800 \mu \mathrm{g}$ the day before infection (50). Mouse infection and analysis of malaria liver stage burden was as previously described $(49,51)$. Briefly, BALB/cJ mice were anesthetized and infected with the bites of 20 PyGLuc infected mosquitoes, respectively. Malaria liver stage burden was measured at the end of liver stage development (45 hours post infection) using an In Vivo Imaging System (IVIS) to determine if blocking PDGFR $\beta$ resulted in lower malaria liver stage infection. From day 3 post infection, mice were monitored daily for the presence of erythrocytic stages by Giemsa staining of thin blood smears.

\section{Statistical Analysis}

All statistical analyses were performed using GraphPad Prism software (version $6)$, and differences considered statistically significant when p was $<0.05$. 


\section{Data availability}

All data presented are contained within the article and the Supporting Information.

\section{Acknowledgements}

We would like to thank the Seattle Children's Research Institute insectary staff, principally Heather Kain, for the help with mosquito production. We also thank Drs. S. Mikolajczak and E. Flannery (Novartis Institute for Tropical Diseases) for assistance with the design of the $P$. vivax TRAP protein.

\section{Funding and additional information}

Our work was supported by National Institutes of Health Grants R01Al134956 (S.H.I.K), R01Al117234 (D.N.S. and S.H.I.K), K25Al119229 (K.E.S), R01GM087221 (R.L.M.). The content is solely the responsibility of the authors and does not necessarily represent the official views of the National Institutes of Health.

\section{Conflict of interest statement}

The authors declare that they have no conflicts of interest with the contents of this article. 
bioRxiv preprint doi: https://doi.org/10.1101/2020.05.12.091488; this version posted May 13, 2020. The copyright holder for this preprint (which

was not certified by peer review) is the author/funder, who has granted bioRxiv a license to display the preprint in perpetuity. It is made available under aCC-BY 4.0 International license.

\section{ORCID iDs}

Ryan W. J. Steel https://orcid.org/0000-0002-4802-2896

Vladimir Vigdorovich https://orcid.org/0000-0003-4195-4858

Kristian E. Swearingen https://orcid.org/0000-0002-6756-4471

Robert L. Moritz https://orcid.org/0000-0002-3216-9447

D. Noah Sather https://orcid.org/0000-0002-9128-172X 


\section{$\underline{\text { References }}$}

1. Geneva: World Health Organization (2019) World malaria report 2019

2. Medica, D. L., and Sinnis, P. (2005) Quantitative dynamics of Plasmodium yoelii sporozoite transmission by infected anopheline mosquitoes. Infect. Immun. 73, 4363-4369

3. Amino, R., Thiberge, S., Martin, B., Celli, S., Shorte, S., Frischknecht, F., and Ménard, R. (2006) Quantitative imaging of Plasmodium transmission from mosquito to mammal. Nat.

Med. 12, 220-224

4. Ejigiri, I., and Sinnis, P. (2009) Plasmodium sporozoite-host interactions from the dermis to the hepatocyte. Curr. Opin. Microbiol. 12, 401-407

5. Frevert, U., Engelmann, S., Zougbédé, S., Stange, J., Ng, B., Matuschewski, K., Liebes, L., and Yee, H. (2005) Intravital observation of Plasmodium berghei sporozoite infection of the liver. PLoS Biol. 3, e192

6. Mota, M. M., Pradel, G., Vanderberg, J. P., Hafalla, J. C., Frevert, U., Nussenzweig, R. S., Nussenzweig, V., and Rodríguez, A. (2001) Migration of Plasmodium sporozoites through cells before infection. Science. 291, 141-144

7. Tavares, J., Formaglio, P., Thiberge, S., Mordelet, E., Van Rooijen, N., Medvinsky, A., Ménard, R., and Amino, R. (2013) Role of host cell traversal by the malaria sporozoite during liver infection. J. Exp. Med. 210, 905-915

8. Prudêncio, M., Rodriguez, A., and Mota, M. M. (2006) The silent path to thousands of merozoites: the Plasmodium liver stage. Nat. Rev. Microbiol. 4, 849-856

9. Cowman, A. F., Berry, D., and Baum, J. (2012) The cellular and molecular basis for malaria parasite invasion of the human red blood cell. J. Cell Biol. 198, 961-971

10. Vaughan, A. M., Aly, A. S. I., and Kappe, S. H. I. (2008) Malaria parasite pre-erythrocytic stage infection: Gliding and hiding. Cell Host Microbe. 4, 209-218

11. Kappe, S., Bruderer, T., Gantt, S., Fujioka, H., Nussenzweig, V., and Menard, R. (1999) Conservation of a gliding motility and cell invasion machinery in Apicomplexan parasites. $J$. Cell Biol. 147, 937-943

12. Morahan, B. J., Wang, L., and Coppel, R. L. (2009) No TRAP, no invasion. Trends Parasitol. 25, 77-84

13. Ejigiri, I., Ragheb, D. R. T., Pino, P., Coppi, A., Bennett, B. L., Soldati-Favre, D., and Sinnis, P. (2012) Shedding of TRAP by a Rhomboid Protease from the Malaria Sporozoite Surface Is Essential for Gliding Motility and Sporozoite Infectivity. PLoS Pathog. 10.1371/journal.ppat.1002725

14. Buscaglia, C. A., Coppens, I., Hol, W. G. J., and Nussenzweig, V. (2003) Sites of interaction between aldolase and thrombospondin-related anonymous protein in Plasmodium. Mol. Biol. Cell. 14, 4947-4957

15. Bergman, L. W., Kaiser, K., Fujioka, H., Coppens, I., Daly, T. M., Fox, S., Matuschewski, K., Nussenzweig, V., and Kappe, S. H. I. (2003) Myosin A tail domain interacting protein (MTIP) localizes to the inner membrane complex of Plasmodium sporozoites. J. Cell Sci. 116, 39-49

16. Gantt, S., Persson, C., Rose, K., Birkett, A. J., Abagyan, R., and Nussenzweig, V. (2000) Antibodies against thrombospondin-related anonymous protein do not inhibit Plasmodium sporozoite infectivity in vivo. Infect. Immun. 68, 3667-3673

17. Matuschewski, K., Nunes, A. C., Nussenzweig, V., and Menard, R. (2002) Plasmodium sporozoite invasion into insect and mammalian cells is directed by the same dual binding system. EMBO J. 21, 1597-1606 
18. Mota, M. M., Thathy, V., Nussenzweig, R. S., and Nussenzweig, V. (2001) Gene targeting in the rodent malaria parasite Plasmodium yoelii. Mol. Biochem. Parasitol. 113, 271-278

19. Song, G. J., Koksal, A. C., Lu, C. F., and Springer, T. A. (2012) Shape change in the receptor for gliding motility in Plasmodium sporozoites. Proc. Natl. Acad. Sci. U. S. A. 109, 21420-21425

20. Hodgson, S. H., Ewer, K. J., Bliss, C. M., Edwards, N. J., Rampling, T., Anagnostou, N. A., de Barra, E., Havelock, T., Bowyer, G., Poulton, I. D., de Cassan, S., Longley, R., Illingworth, J. J., Douglas, A. D., Mange, P. B., Collins, K. A., Roberts, R., Gerry, S., Berrie, E., Moyle, S., Colloca, S., Cortese, R., Sinden, R. E., Gilbert, S. C., Bejon, P., Lawrie, A. M., Nicosia, A., Faust, S. N., and Hill, A. V. S. (2015) Evaluation of the Efficacy of ChAd63-MVA Vectored Vaccines Expressing Circumsporozoite Protein and ME-TRAP Against Controlled Human Malaria Infection in Malaria-Naive Individuals. J. Infect. Dis. 211, 1076-1086

21. Ogwang, C., Kimani, D., Edwards, N. J., Roberts, R., Mwacharo, J., Bowyer, G., Bliss, C., Hodgson, S. H., Njuguna, P., Viebig, N. K., Nicosia, A., Gitau, E., Douglas, S., Illingworth, J., Marsh, K., Lawrie, A., Imoukhuede, E. B., Ewer, K., Urban, B. C., Hill, A. V. S., Bejon, P., and Grp, M. (2015) Prime-boost vaccination with chimpanzee adenovirus and modified vaccinia Ankara encoding TRAP provides partial protection against Plasmodium falciparum infection in Kenyan adults. Sci. Transl. Med. 10.1126/scitranslmed.aaa2373

22. Cabral-Miranda, G., Heath, M. D., Mohsen, M. O., Gomes, A. C., Engeroff, P., Flaxman, A., Leoratti, F. M. S., El-Turabi, A., Reyes-Sandoval, A., Skinner, M. A., Kramer, M. F., and Bachmann, M. F. (2017) Virus-Like Particle (VLP) Plus Microcrystalline Tyrosine (MCT) Adjuvants Enhance Vaccine Efficacy Improving $T$ and B Cell Immunogenicity and Protection against Plasmodium berghei/vivax. Vaccines. 10.3390/vaccines5020010

23. Kester, K. E., Gray Heppner, D., Jr, Moris, P., Ofori-Anyinam, O., Krzych, U., Tornieporth, N., McKinney, D., Delchambre, M., Ockenhouse, C. F., Voss, G., Holland, C., Beckey, J. P., Ballou, W. R., Cohen, J., and RTS,S/TRAP Group (2014) Sequential Phase 1 and Phase 2 randomized, controlled trials of the safety, immunogenicity and efficacy of combined pre-erythrocytic vaccine antigens RTS,S and TRAP formulated with AS02 Adjuvant System in healthy, malaria naïve adults. Vaccine. 32, 6683-6691

24. Bauza, K., Malinauskas, T., Pfander, C., Anar, B., Jones, E. Y., Billker, O., Hill, A. V. S., and Reyes-Sandoval, A. (2014) Efficacy of a Plasmodium vivax malaria vaccine using ChAd63 and modified vaccinia Ankara expressing thrombospondin-related anonymous protein as assessed with transgenic Plasmodium berghei parasites. Infect. Immun. 82, 1277-1286

25. Shen, J., Vil, M. D., Prewett, M., Damoci, C., Zhang, H., Li, H., Jimenez, X., Deevi, D. S., lacolina, M., Kayas, A., Bassi, R., Persaud, K., Rohoza-Asandi, A., Balderes, P., Loizos, N., Ludwig, D. L., Tonra, J., Witte, L., and Zhu, Z. (2009) Development of a fully human anti-PDGFRbeta antibody that suppresses growth of human tumor xenografts and enhances antitumor activity of an anti-VEGFR2 antibody. Neoplasia. 11, 594-604

26. Dundas, K., Shears, M. J., Sun, Y., Hopp, C. S., Crosnier, C., Metcalf, T., Girling, G., Sinnis, P., Billker, O., and Wright, G. J. (2018) Alpha-v-containing integrins are host receptors for the Plasmodium falciparum sporozoite surface protein, TRAP. Proceedings of the National Academy of Sciences. 10.1073/pnas.1719660115

27. Vaughan, A. M., and Kappe, S. H. I. (2017) Malaria Parasite Liver Infection and Exoerythrocytic Biology. Cold Spring Harb. Perspect. Med. 10.1101/cshperspect.a025486

28. Kaushansky, A., Douglass, A. N., Arang, N., Vigdorovich, V., Dambrauskas, N., Kain, H. S., Austin, L. S., Sather, D. N., and Kappe, S. H. (2015) Malaria parasites target the 
hepatocyte receptor EphA2 for successful host infection. Science. 350, 1089-1092

29. Silvie, O., Rubinstein, E., Franetich, J.-F., Prenant, M., Belnoue, E., Renia, L., Hannoun, L., Eling, W., Levy, S., Boucheix, C., and Mazier, D. (2003) Hepatocyte CD81 is required for Plasmodium falciparum and Plasmodium yoelii sporozoite infectivity. Nat. Med. 9, 93-96

30. Rodrigues, C. D., Hannus, M., Prudêncio, M., Martin, C., Gonçalves, L. A., Portugal, S., Epiphanio, S., Akinc, A., Hadwiger, P., Jahn-Hofmann, K., Röhl, I., van Gemert, G.-J., Franetich, J.-F., Luty, A. J. F., Sauerwein, R., Mazier, D., Koteliansky, V., Vornlocher, H.-P., Echeverri, C. J., and Mota, M. M. (2008) Host scavenger receptor SR-BI plays a dual role in the establishment of malaria parasite liver infection. Cell Host Microbe. 4, 271-282

31. Manzoni, G., Marinach, C., Topcu, S., Briquet, S., Grand, M., Tolle, M., Gransagne, M., Lescar, J., Andolina, C., Franetich, J. F., Zeisel, M. B., Huby, T., Rubinstein, E., Snounou, G., Mazier, D., Nosten, F., Baumert, T. F., and Silvie, O. (2017) Plasmodium P36 determines host cell receptor usage during sporozoite invasion. Elife. 10.7554/eLife.25903

32. Miyazaki, H., Yoshimatsu, Y., Akatsu, Y., Mishima, K., Fukayama, M., Watabe, T., and Miyazono, K. (2014) Expression of platelet-derived growth factor receptor $\beta$ is maintained by Prox1 in lymphatic endothelial cells and is required for tumor lymphangiogenesis. Cancer Sci. 105, 1116-1123

33. Andrae, J., Gallini, R., and Betsholtz, C. (2008) Role of platelet-derived growth factors in physiology and medicine. Genes Dev. 22, 1276-1312

34. Kazlauskas, A. (2017) PDGFs and their receptors. Gene. 614, 1-7

35. Werner, S., and Grose, R. (2003) Regulation of wound healing by growth factors and cytokines. Physiol. Rev. 83, 835-870

36. Harupa, A., Sack, B. K., Lakshmanan, V., Arang, N., Douglass, A. N., Oliver, B. G., Stuart, A. B., Sather, D. N., Lindner, S. E., Hybiske, K., Torii, M., and Kappe, S. H. I. (2014) SSP3 Is a Novel Plasmodium yoelii Sporozoite Surface Protein with a Role in Gliding Motility. Infect. Immun. 82, 4643-4653

37. Carbonetti, S., Oliver, B. G., Vigdorovich, V., Dambrauskas, N., Sack, B., Bergl, E., Kappe, S. H. I., and Sather, D. N. (2017) A method for the isolation and characterization of functional murine monoclonal antibodies by single B cell cloning. J. Immunol. Methods. 448, 66-73

38. Wang, J.-Y., Song, W.-T., Li, Y., Chen, W.-J., Yang, D., Zhong, G.-C., Zhou, H.-Z., Ren, C.-Y., Yu, H.-T., and Ling, H. (2011) Improved expression of secretory and trimeric proteins in mammalian cells via the introduction of a new trimer motif and a mutant of the tPA signal sequence. Appl. Microbiol. Biotechnol. 91, 731-740

39. Beckett, D., Kovaleva, E., and Schatz, P. J. (1999) A minimal peptide substrate in biotin holoenzyme synthetase-catalyzed biotinylation. Protein Sci. 8, 921-929

40. Swearingen, K. E., Lindner, S. E., Flannery, E. L., Vaughan, A. M., Morrison, R. D., Patrapuvich, R., Koepfli, C., Muller, I., Jex, A., Moritz, R. L., Kappe, S. H. I., Sattabongkot, J., and Mikolajczak, S. A. (2017) Proteogenomic analysis of the total and surface-exposed proteomes of Plasmodium vivax salivary gland sporozoites. PLoS Negl. Trop. Dis. 11, e0005791

41. Carlton, J. M., Adams, J. H., Silva, J. C., Bidwell, S. L., Lorenzi, H., Caler, E., Crabtree, J., Angiuoli, S. V., Merino, E. F., Amedeo, P., Cheng, Q., Coulson, R. M., Crabb, B. S., Del Portillo, H. A., Essien, K., Feldblyum, T. V., Fernandez-Becerra, C., Gilson, P. R., Gueye, A. H., Guo, X., Kang'a, S., Kooij, T. W., Korsinczky, M., Meyer, E. V., Nene, V., Paulsen, I., White, O., Ralph, S. A., Ren, Q., Sargeant, T. J., Salzberg, S. L., Stoeckert, C. J., Sullivan, S. A., Yamamoto, M. M., Hoffman, S. L., Wortman, J. R., Gardner, M. J., Galinski, M. R., Barnwell, J. W., and Fraser-Liggett, C. M. (2008) Comparative genomics of the neglected 
human malaria parasite Plasmodium vivax. Nature. 455, 757-763

42. Auburn, S., Bohme, U., Steinbiss, S., Trimarsanto, H., Hostetler, J., Sanders, M., Gao, Q., Nosten, F., Newbold, C. I., Berriman, M., Price, R. N., and Otto, T. D. (2016) A new Plasmodium vivax reference sequence with improved assembly of the subtelomeres reveals an abundance of pir genes. Wellcome Open Res. 1, 4

43. Jex, A., Mueller, I., Kappe, S., Mikolajcjak, S., Sattabongkot, J., Patrapuvich, R., Lindner, S., Flannery, E., Koepfli, C., Ansell, B., Lerch, A., Swearingen, K. E., Moritz, R. L., Petter, M., Duffy, M., and Chuenchob, V. (2017) Integrated transcriptomic, proteomic and epigenomic analysis of Plasmodium vivax salivary-gland sporozoites. bioRxiv. 10.1101/145250

44. von Itzstein, M., Plebanski, M., Cooke, B. M., and Coppel, R. L. (2008) Hot, sweet and sticky: the glycobiology of Plasmodium falciparum. Trends Parasitol. 24, 210-218

45. Bushkin, G. G., Ratner, D. M., Cui, J., Banerjee, S., Duraisingh, M. T., Jennings, C. V., Dvorin, J. D., Gubbels, M.-J., Robertson, S. D., Steffen, M., O'Keefe, B. R., Robbins, P. W., and Samuelson, J. (2010) Suggestive evidence for Darwinian Selection against asparagine-linked glycans of Plasmodium falciparum and Toxoplasma gondii. Eukaryot. Cell. 9, 228-241

46. Swearingen, K. E., Lindner, S. E., Flannery, E. L., Vaughan, A. M., Morrison, R. D., Patrapuvich, R., Koepfli, C., Muller, I., Jex, A., Moritz, R. L., Kappe, S. H. I., Sattabongkot, J., and Mikolajczak, S. A. (2017) Proteogenomic analysis of the total and surface-exposed proteomes of Plasmodium vivax salivary gland sporozoites. PLoS Negl. Trop. Dis. 11, e0005791

47. Carbonetti, S., Oliver, B. G., Glenn, J., Stamatatos, L., and Sather, D. N. (2014) Soluble HIV-1 envelope immunogens derived from an elite neutralizer elicit cross-reactive V1V2 antibodies and low potency neutralizing antibodies. PLoS One. 9, e86905

48. Backliwal, G., Hildinger, M., Hasija, V., and Wurm, F. M. (2008) High-density transfection with HEK-293 cells allows doubling of transient titers and removes need for a priori DNA complex formation with PEI. Biotechnol. Bioeng. 99, 721-727

49. Miller, J. L., Murray, S., Vaughan, A. M., Harupa, A., Sack, B., Baldwin, M., Crispe, I. N., and Kappe, S. H. (2013) Quantitative bioluminescent imaging of pre-erythrocytic malaria parasite infection using luciferase-expressing Plasmodium yoelii. PLoS One. 8, e60820

50. Foquet, L., Hermsen, C. C., Verhoye, L., van Gemert, G. J., Cortese, R., Nicosia, A., Sauerwein, R. W., Leroux-Roels, G., and Meuleman, P. (2015) Anti-CD81 but not anti-SR-BI blocks Plasmodium falciparum liver infection in a humanized mouse model. $J$. Antimicrob. Chemother. 70, 1784-1787

51. Sack, B. K., Miller, J. L., Vaughan, A. M., Douglass, A., Kaushansky, A., Mikolajczak, S., Coppi, A., Gonzalez-Aseguinolaza, G., Tsuji, M., Zavala, F., Sinnis, P., and Kappe, S. H. I. (2014) Model for In Vivo Assessment of Humoral Protection against Malaria Sporozoite Challenge by Passive Transfer of Monoclonal Antibodies and Immune Serum. Infect. Immun. 82, 808-817 
bioRxiv preprint doi: https://doi.org/10.1101/2020.05.12.091488; this version posted May 13, 2020. The copyright holder for this preprint (which

was not certified by peer review) is the author/funder, who has granted bioRxiv a license to display the preprint in perpetuity. It is made available under aCC-BY 4.0 International license.

\section{Footnotes}

The abbreviations used are: TRAP, thrombospondin-related anonymous protein; VWA, von Willebrand factor A; MIDAS, metal ion-dependent adhesion site; TSR, thrombospondin repeat; HSPGs, heparan sulfate proteoglycans; hPDGFRß, human platelet-derived growth factor receptor $\beta$; gMFI, geometric mean fluorescence intensity. 


\section{Tables}

\section{Table 1: Protein constructs}

\begin{tabular}{|c|c|c|}
\hline Protein (Database Reference) & Domain(s) & Amino Acids \\
\hline PfTRAP (PlasmoDB:PF3D7_1335900) & Full Ectodomain & $26-513$ \\
\hline & VWA+TSR & $26-288$ \\
\hline & VWA & $26-244$ \\
\hline & TSR & $241-292$ \\
\hline & TSR + Repeats & $243-513$ \\
\hline & Repeats & $291-513$ \\
\hline PvTRAP (PlasmoDB:PVX_082735, & Full Ectodomain & $25-493$ \\
PlasmoDB:PVP01_1218700) & & \\
\hline PyTRAP (PlasmoDB:PYYM_1351500) & Full Ectodomain & $23-763$ \\
\hline & VWA+TSR & $23-281$ \\
\hline PDGF-BB (GenBank: CAG30424.1) & Ectodomain & $82-190$ \\
\hline hPDGFRß (GenBank: BC032224.1) & Ectodomain & $33-532$ \\
\hline
\end{tabular}

${ }^{1}$ Protein sequence was modified, as described in the main text. 
Figures and figure legends

Figure 1: The VWA and TSR domains of PfTRAP act together to bind human PDGFRß.

A

native

Full ECD VWA + TSR (D)

VWA

TSR

TSR + Repeats (

Repeats

(F)

(H)
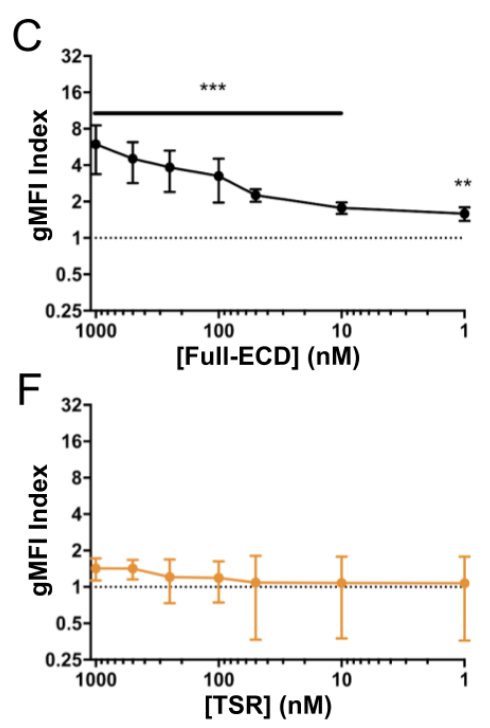

(E)

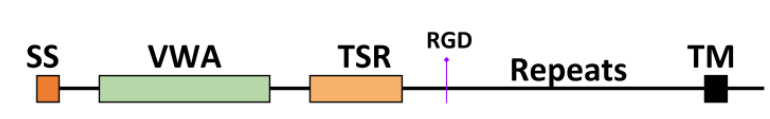

B,C)
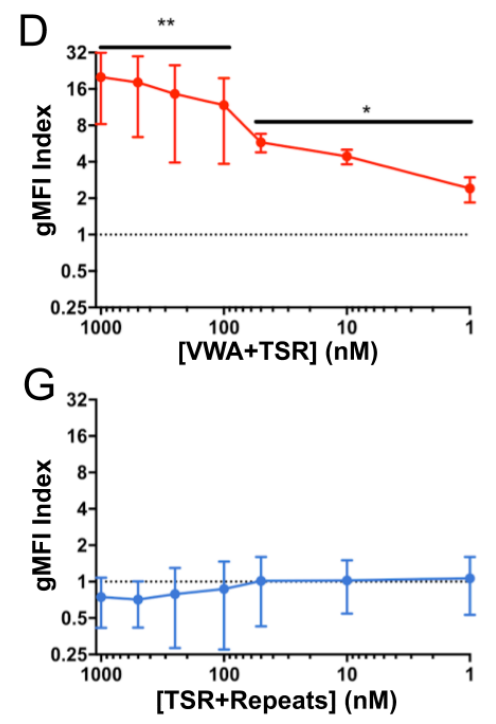

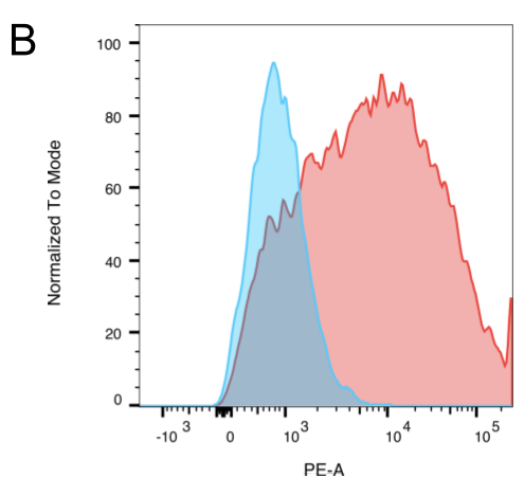

E
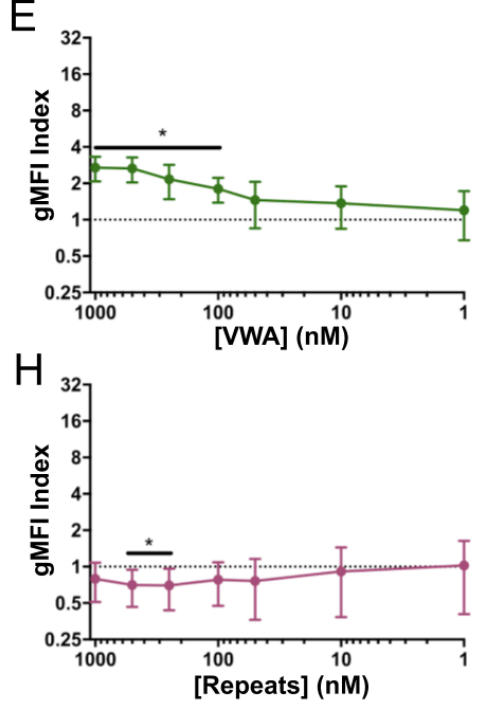

(A) Overlapping constructs containing various domains of TRAP are represented as a

schematic and were similarly used in further experiments. (B) Biotinylated and

fluorescently-labeled PfTRAP ectodomain binds preferentially to the HEK293F cells transfected with hPDGFR (red) over untransfected cells (blue) within the same culture. Titration experiments $(\mathrm{C}-\mathrm{H})$ using increasing dilution of fluorescently labeled fragments of PfTRAP were quantitated as a ratio of binding to transfected versus untransfected cells (gMFI Index) across a 3-log concentration range. Fragments of PfTRAP containing 
the VWA and TSR domains together bound PDGFR $\beta$ strongly across a 3-log range (C, D). While the VWA domain alone showed significant binding to hPDGFR $\beta$ at concentrations of $100 \mathrm{nM}$ and above (E), the TSR fragment, the repeat region, or the TSR fragment plus the repeat region did not bind significantly $(\mathrm{F}-\mathrm{H})$. Data are the mean \pm SD from at least five independent experiments. Analysis by one sample t-test compared to the dashed line (gMFI index expected if no specific binding occurs); ${ }^{*} p<0.05,{ }^{* *} p<0.01,{ }^{* * *} p<0.001$ 
Figure 2: hPDGFR $\beta$ is expressed in the basement membrane of vessels in the skin, and around large blood vessels in the liver.
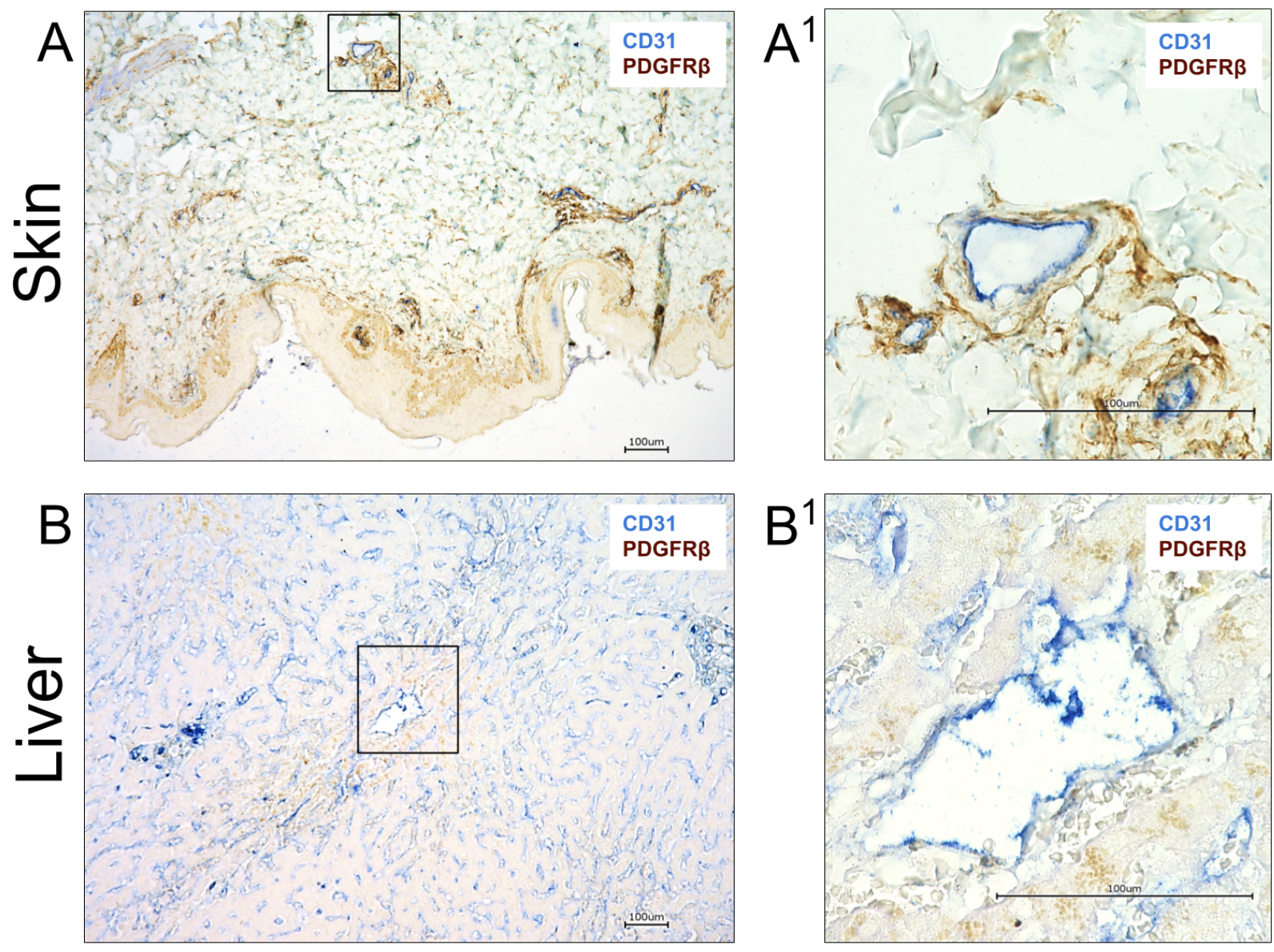

Formalin fixed paraffin embedded sections of normal human skin and liver were stained for CD31 (blue) and PDGFR $\beta$ (brown). (A) Staining for the endothelial marker CD31 could be seen in the lumen of all skin vasculature irrespective of the size. PDGFR $\beta$ was detected surrounding these vascular structures but was not associated with the luminal side of the vessel. Boxed area enlarged in $A^{1}$. (B) CD31 staining was observed in liver sinusoidal endothelial cells (LSEC) all throughout the liver and also in the lumen of 
bioRxiv preprint doi: https://doi.org/10.1101/2020.05.12.091488; this version posted May 13, 2020. The copyright holder for this preprint (which

was not certified by peer review) is the author/funder, who has granted bioRxiv a license to display the preprint in perpetuity. It is made available under aCC-BY 4.0 International license.

major blood vessels. Very low levels of PDGFR $\beta$ staining was detected surrounding large blood vessels but was not associated with the luminal surface of the vessel. No

PDGFR $\beta$ staining was seen around LSECs. Boxed area enlarged in $B^{1}$. Scale bars are $100 \mu \mathrm{m}$. 
Figure 3: PfTRAP interaction with human PDGFR $\beta$ can be disrupted by parasite and host directed antibodies.
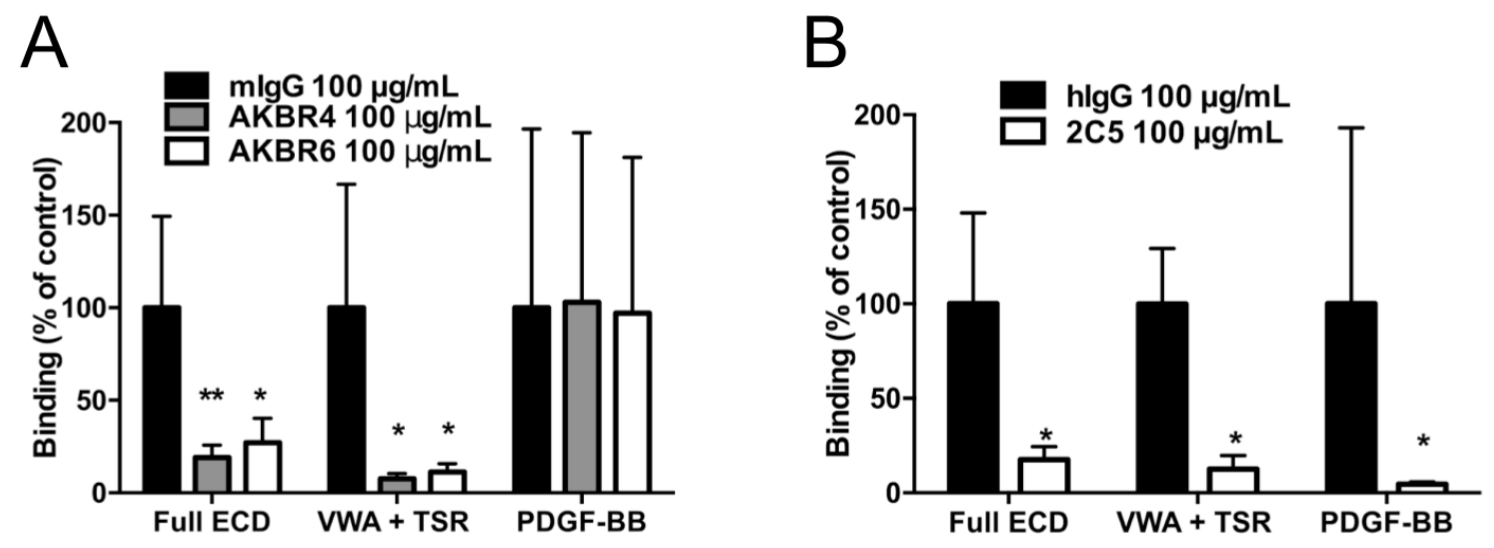

(A) Anti-PfTRAP mAb AKBR4 or AKBR6 was incubated with 1000 nM PfTRAP full ectodomain (ECD) or VWA+TSR fragment, or $10 \mathrm{nM}$ of the known PDGFR $\beta$ ligand hPDGF-BB for 30 minutes before addition to hPDGFR $\beta$ transfected cells in the flow assay. Binding of the Full ECD and VWA+TSR fragments was reduced by approximately $80 \%$ and $90 \%$, respectively, while binding of human PDGF-BB was unaffected. (B) hPDGFR -transfected cells were incubated with anti-PDGFR $\mathrm{mAb}$ 2C5 for 30 minutes before addition of staining reagents as above with analysis by flow cytometry. Blocking hPDGFR $\beta$ inhibited binding of both PfTRAP fragments as well as the known ligand human PDGF-BB. Data are normalized to appropriate isotype controls and represent the mean \pm SD from four independent experiments. Analysis by One-way ANOVA with Dunnet's multiple comparisons test $(A)$, and Mann Whitney test (B); ${ }^{*} p<0.05,{ }^{* *} p<0.01$ compared to the isotype control. 
Figure 4: Divalent cations and $\alpha v$-integrin do not contribute to PfTRAP binding of human PDGFR $\beta$.
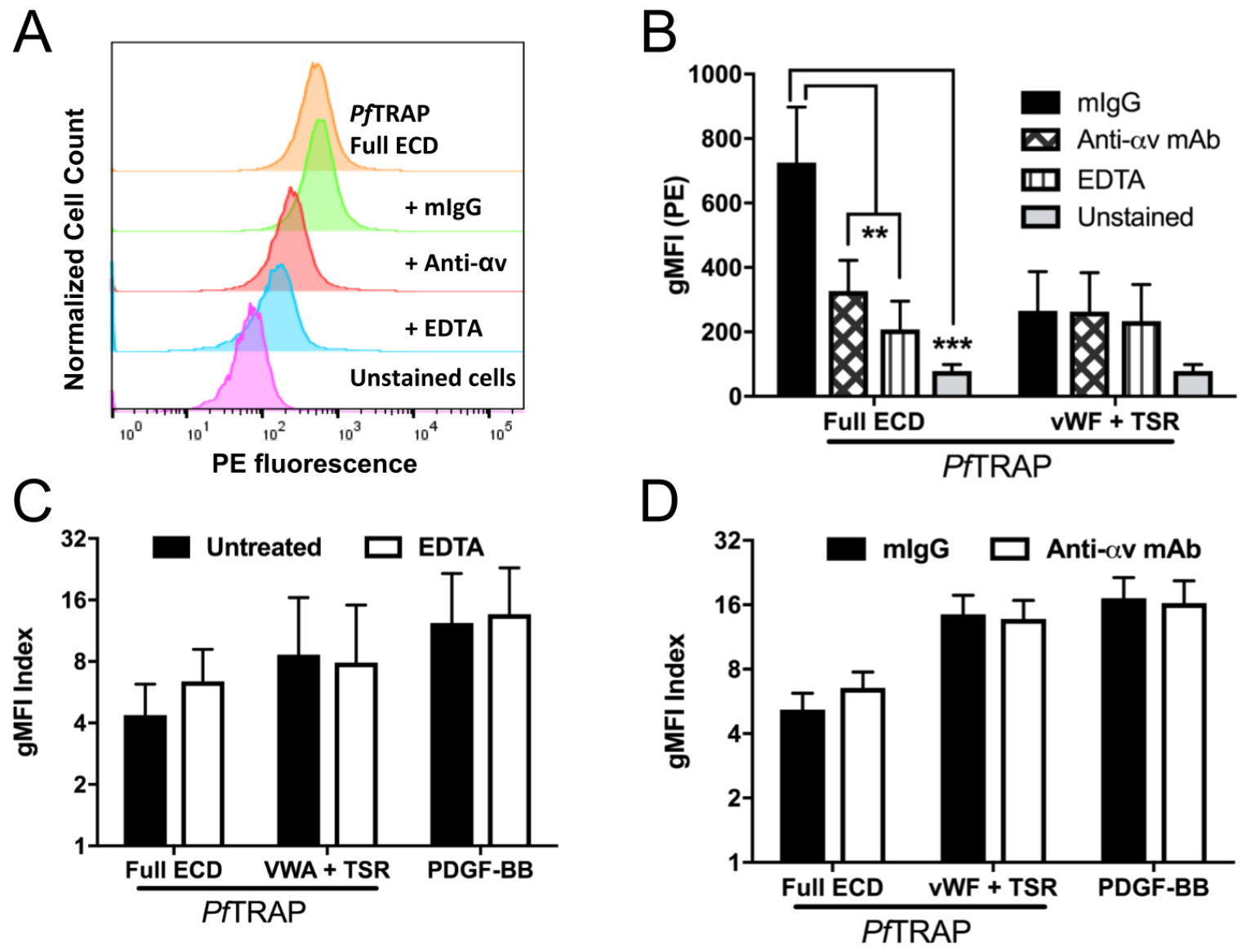

(A, B) PfTRAP ectodomain (Full ECD) staining reagent at $1000 \mathrm{nM}$ bound to untransfected HEK293F cells. This binding was inhibited by both $10 \mathrm{mM}$ EDTA and 10 $\mu \mathrm{g} / \mathrm{mL}$ of anti-av-integrin mAb, but not an isotype control antibody. (B) The VWA+TSR fragment of PfTRAP did not bind significantly to untransfected cells and was not affected by EDTA or anti-av-integrin antibodies. (C, D) Presence of 10 mM EDTA or 10 ug/mL anti- $\alpha$-integrin mAb did not significantly affect the binding of PfTRAP ECD (1000 $\mathrm{nM})$, the VWA+TSR fragment (1000 nM) or the natural ligand PDGF-BB $(10 \mathrm{nM})$ to 
bioRxiv preprint doi: https://doi.org/10.1101/2020.05.12.091488; this version posted May 13, 2020. The copyright holder for this preprint (which

was not certified by peer review) is the author/funder, who has granted bioRxiv a license to display the preprint in perpetuity. It is made available under aCC-BY 4.0 International license.

HEK293F cells transfected with human PDGFR $\beta$. Data are the mean \pm SD from at least three independent experiments. Analysis by One-way ANOVA with Dunnet's multiple comparisons test (B), and paired t-test (C-D); ${ }^{*} p<0.05,{ }^{* *} p<0.01,{ }^{* * *} p<0.001$. 
Figure 5: Engagement of PDGFR $\beta$ by TRAP distinguishes human and rodent infective Plasmodium species and is restricted at the level of TRAP.
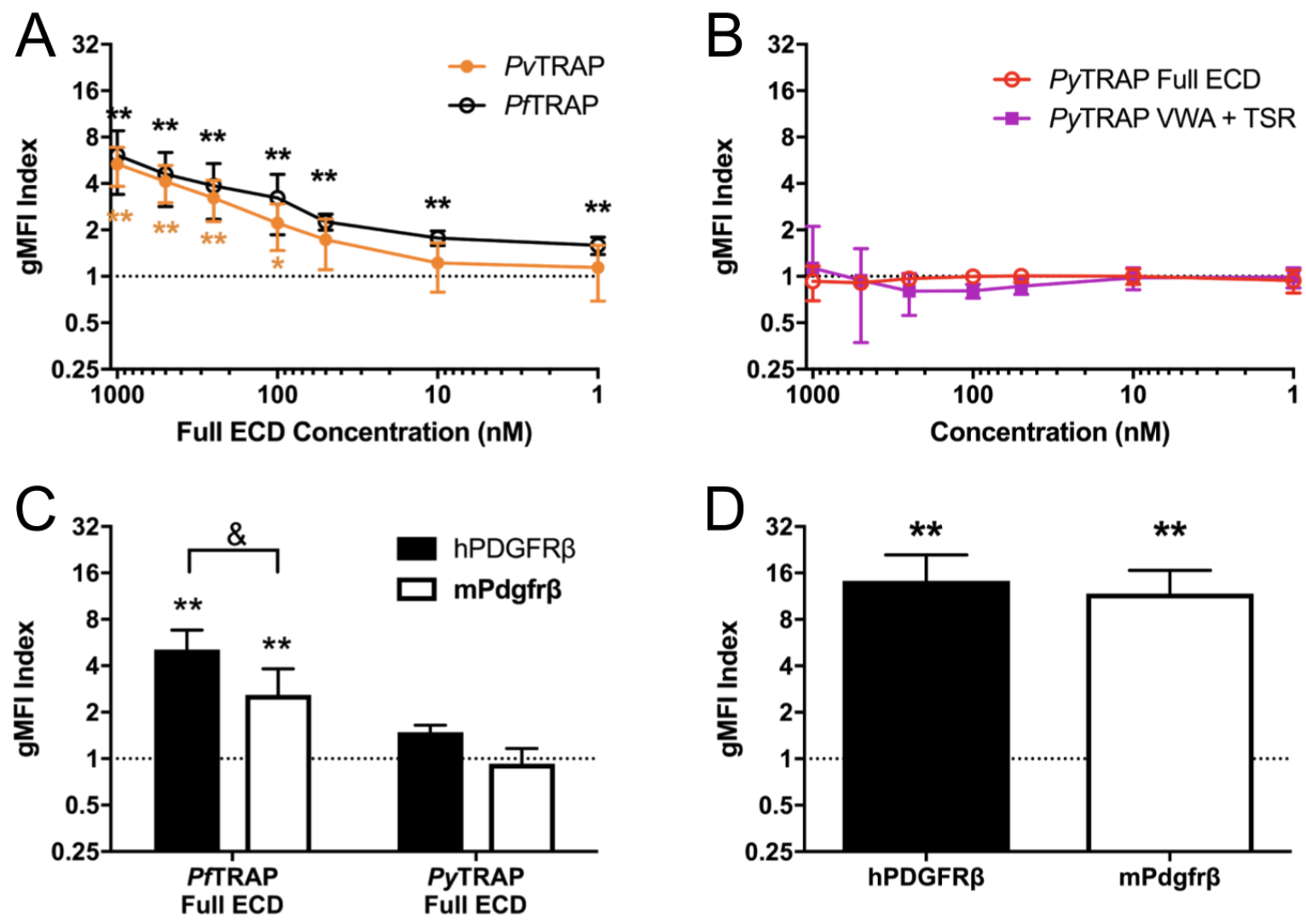

(A) PvTRAP ectodomain (ECD) staining reagent bound HEK293F cells transfected with human PDGFR $\beta$ (hPDGFR $\beta$ ) in a concentration dependent manner that was not different from the binding of PfTRAP ECD. (B) PyTRAP ECD or a fragment containing the VWA+TSR domains did not bind to HEK293F cells transfected with mouse PDGFR $\beta$ (mPDGFR $\beta$ ) at any concentration tested. (C) PfTRAP and PyTRAP ECD were tested at $1000 \mathrm{nM}$ for binding to both hPDGFR $\beta$ and mPDGFR $\beta$ transfected HEK293F cells. PfTRAP ECD bound to both receptors, although less strongly to mPDGFR $\beta$, while 
PyTRAP ECD did not bind to either receptor. (D) Known ligand for hPDGFR $\beta$ and mPDGFR $\beta$, human PDGF-BB bound to both receptors at $10 \mathrm{nM}$. Data are the mean \pm SD from at least three independent experiments. Asterisks indicate analysis by one sample t-test compared to the dashed line (gMFI index expected if no specific binding occurs), ${ }^{*} p<0.05,{ }^{* *} p<0.01$; ampersand indicates analysis by t-test, ${ }^{\circledR} p<0.05$. 


\section{Supporting information}

\section{Supplementary Figure 1: Characterization of recombinant Plasmodium TRAP ectodomains fragments.}

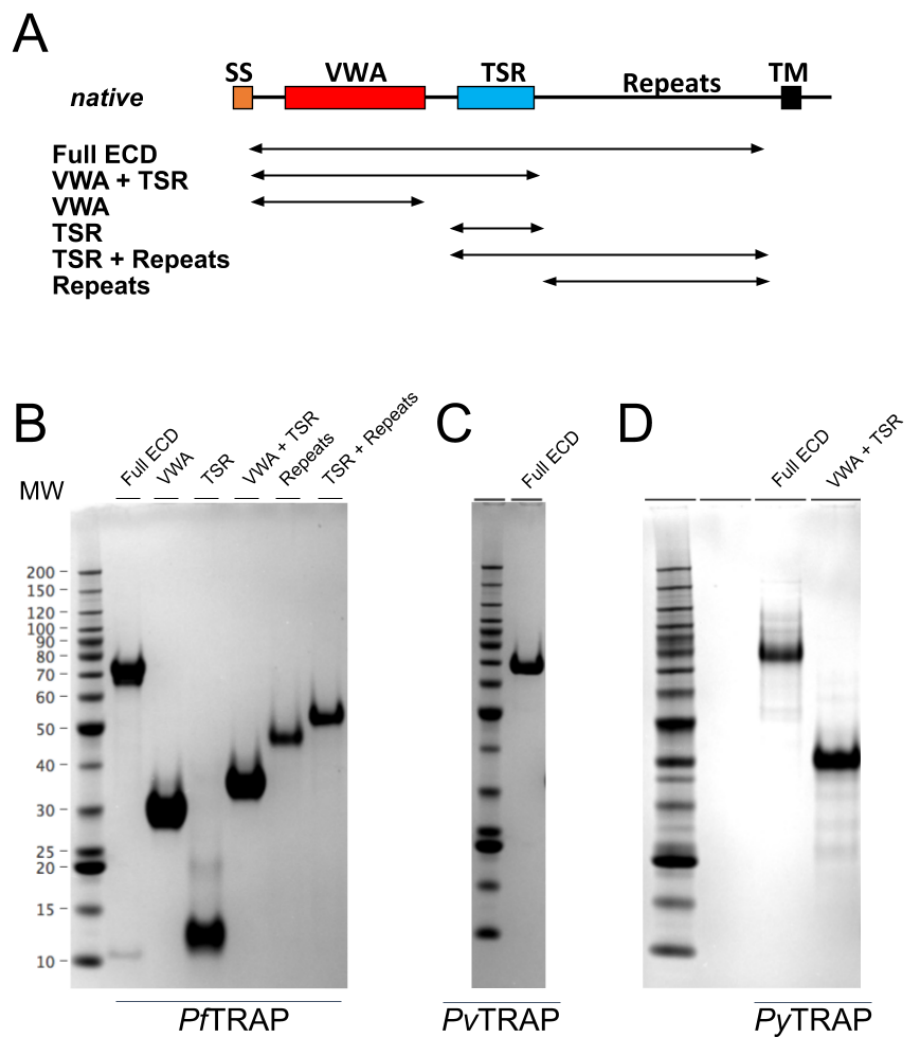

(A) Schematic representation of deletion constructs spanning the ectodomain of TRAP. SDS-PAGE of the six constructs produced using the P. falciparum (B), P. vivax (C), and P. yoelii (D) sequences. Labels for the molecular weight standards are shared across panels B-D. 


\section{Supplementary Figure 2: PfTRAP binds to PDGFR $\beta$ expressed in HEK293 cells using the Retrogenix ${ }^{\circledR}$ Cell Microarray platform.}

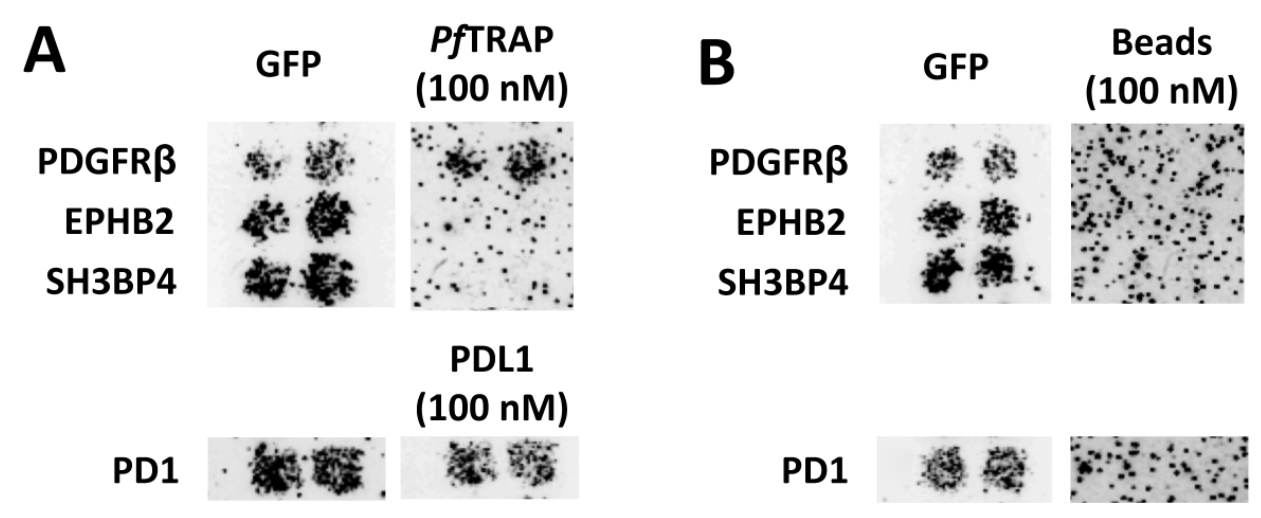

Hits from primary binding screens were re-arrayed for reverse transfection into HEK293 cells in duplicate for secondary specificity and reproducibility screens in conjunction with a GFP reporter construct for successful transfection. Fluorescent beads conjugated with PfTRAP full ECD identified specific binding to PDGFR $\beta$ transfected cells (A) that was not observed with unconjugated beads (B). Positive control ligand, PDL1, oligomerized to fluorescent beads bound strongly and specifically to its known interaction partner PD1. 
Supplementary Figure 3: Analysis of ligand binding by flow cytometry.

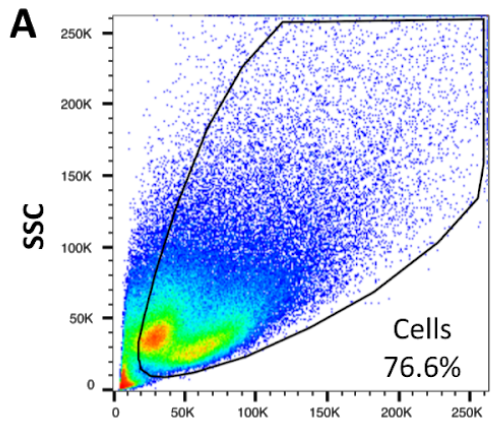

FSC-A
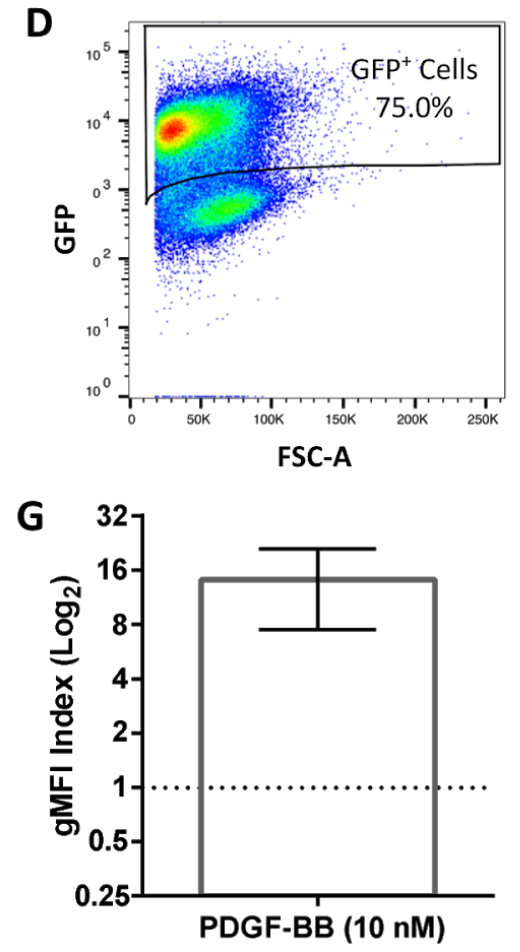

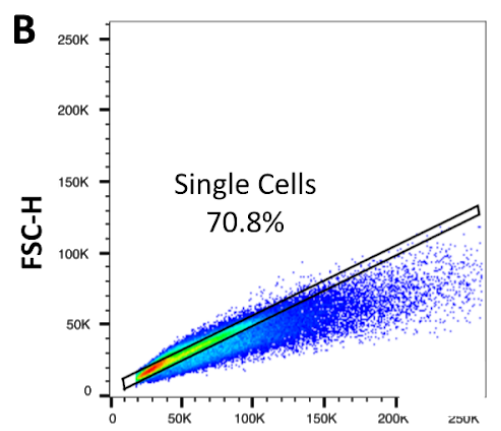

FSC-A

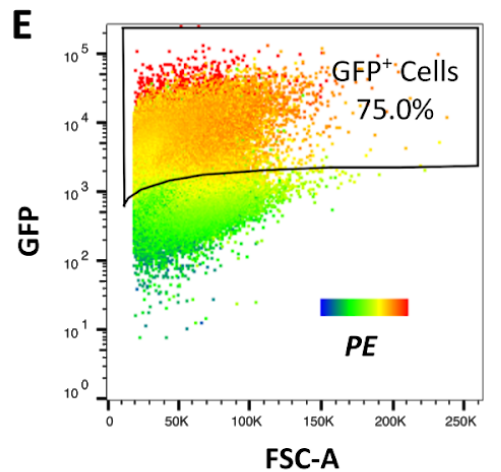

FSC-A

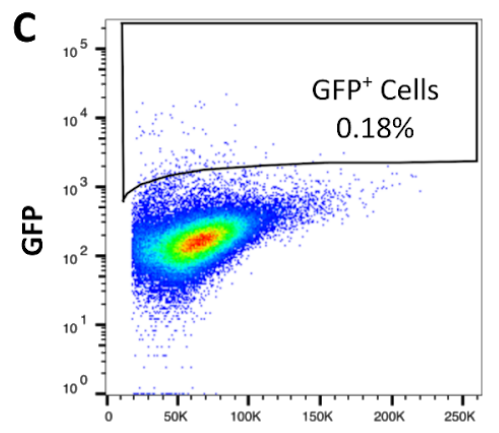

FSC-A

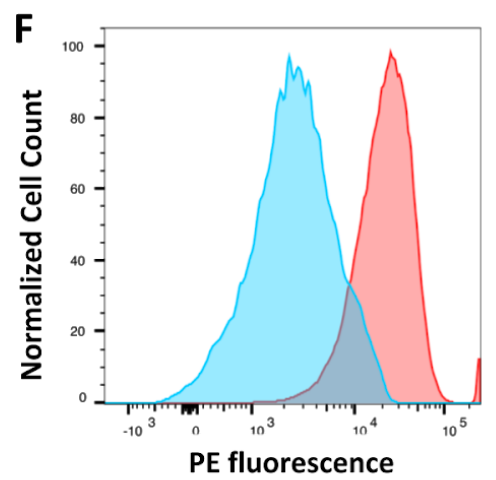

GFP- Cells $=$ GFP $^{+}$Cells

Biotinylated ligand (PDGF-BB in this example) was oligomerized around a streptavidin-conjugated phycoerythrin (PE) staining reagent and incubated with HEK293F cells for 30 minutes before analysis by flow cytometry. Cells were first separated from debris (A) and single cells selected for analysis (B). An untransfected cell sample was used to set the $\mathrm{GFP}^{+}$transfected cell gate (C) from which cells transfected with a GFP-fusion of PDGFR $\beta$ and untransfected GFP ${ }^{-}$cells from within the 
same sample were identified (D). The geometric mean fluorescent intensity (gMFI) of PE staining was used to determine the binding of the oligomerized staining reagent to the transfected and untransfected cell population, for which the positive control ligand human PDGF-BB bound strongly and preferentially to the PDGFR $\beta$ transfected cell population (E). Specificity for binding to the transfected receptor population was measured as the ratio of the gMFIs from GFP' and GFP' cells reported as the 'gMFI Index', and measurements were taken over multiple experiments to ensure the reproducibility of the results $(F-G)$. Data in A-F show a representative experiment. Data in $\mathrm{G}$ are from 7 independent experiments and represent the mean \pm SD; the dashed line represents the gMFI index expected if no specific binding occurs. 
Supplementary Figure 4: Titration of PfTRAP fragment binding to hPDGFR $\beta$ in the flow cytometry binding assay.

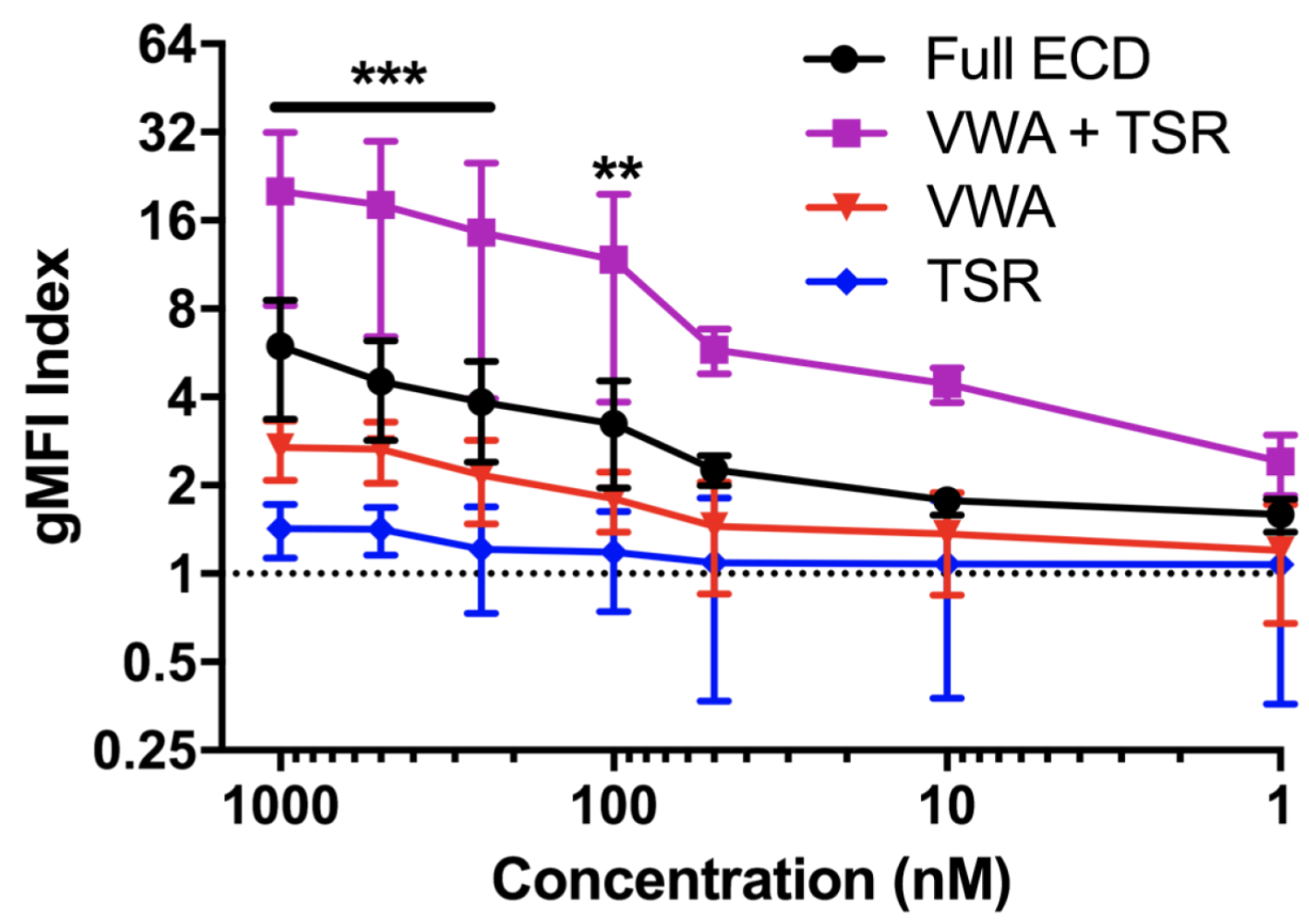

The gMFI index of VWA+TSR fragment bound to PDGFR $\beta$ transfected cells was greater than all other fragments at concentrations at or above $100 \mathrm{nM}$. Data are the same as those in Figure 1 and represent the mean \pm SD from at least five independent experiments. Analysis by Two-Way ANOVA with Bonferroni's multiple comparisons test; asterisks indicate the VWA+TSR fragment is different from all others, ${ }^{* *} p<0.01$, ${ }^{* * *} p<0.001$. 


\section{Supplementary Figure 5: Validation of anti-PDGFR $\beta$ mAb 2 C5 and its use in $P$. yoelii passive transfer studies.}
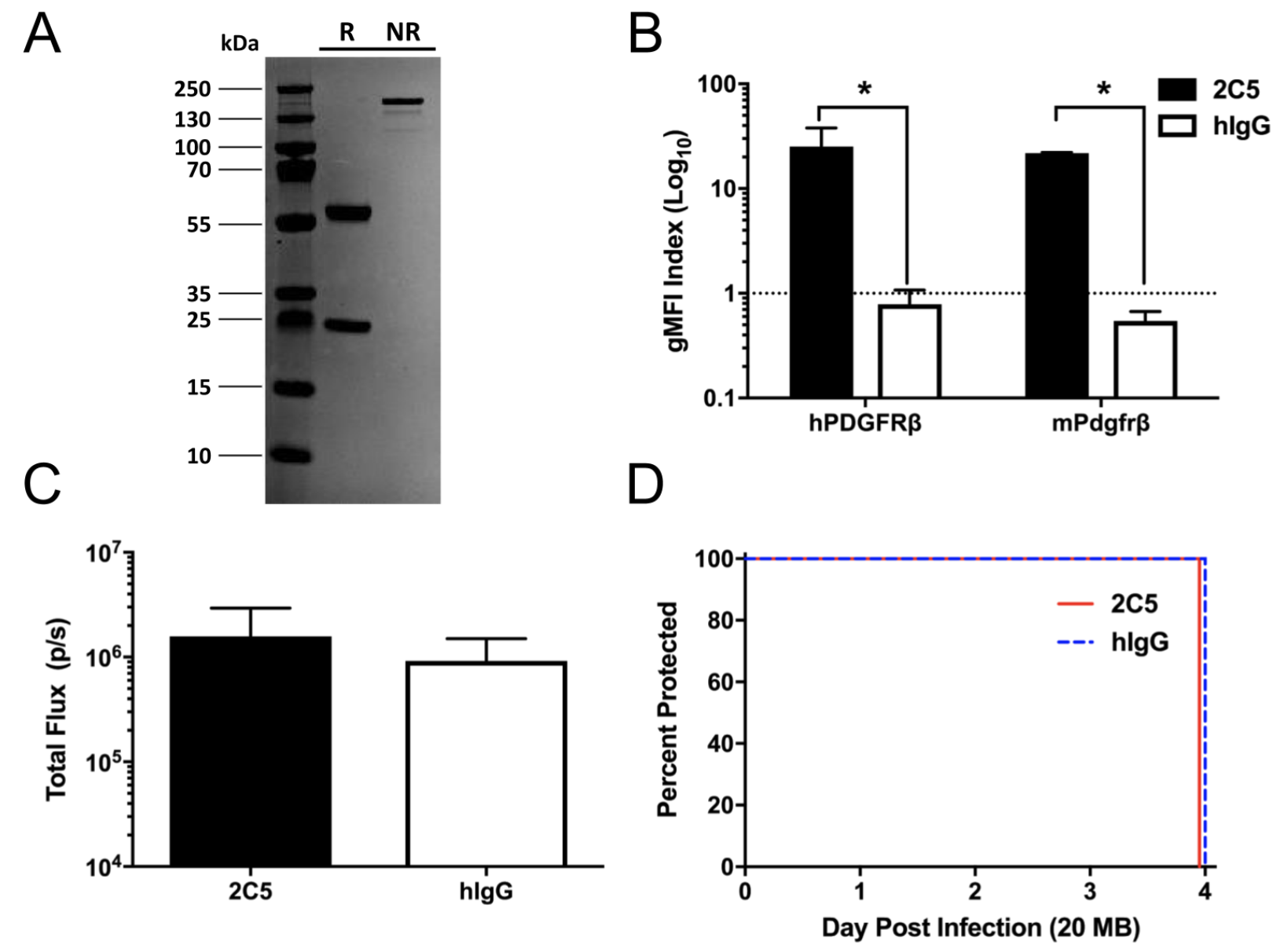

(A) mAb 2C5 was produced as a human IgG1 and analyzed by SDS-PAGE under reducing (R) and non-reducing (NR) conditions. (B) Cells were transfected with human or mouse PDGFR ( $\mathrm{hPDGFR} \beta$ and mPDGFR $\beta$, respectively), then incubated with 100 $\mu \mathrm{g} / \mathrm{mL} \mathrm{mAb} 2 \mathrm{C} 5$ or isotype control before washing and staining with an anti-human antibody to measure mAb $2 \mathrm{C} 5$ specificity for PDGFR . Data are the mean \pm SD from at least 2 independent experiments with analysis by t-test; * $p<0.05$. (C-D) Eighteen hours and one hour before challenge with 20 bites from $P$. yoelii infected mosquitoes, 
bioRxiv preprint doi: https://doi.org/10.1101/2020.05.12.091488; this version posted May 13, 2020. The copyright holder for this preprint (which

was not certified by peer review) is the author/funder, who has granted bioRxiv a license to display the preprint in perpetuity. It is made available under aCC-BY 4.0 International license.

BALB/cJ mice received $800 \mu \mathrm{mAb} 2 \mathrm{C} 5(\mathrm{n}=5)$ or isotype control $(\mathrm{n}=5 ; 1.6 \mathrm{mg}$ of antibody total). There was no difference in the malaria liver stage burden at 45 hours post infection or delay to blood stage patency. 


\section{Supplementary Figure 6: Purified recombinant human PDGFR $\beta$ does not bind purified recombinant PfTRAP in biolayer interferometry experiments.}
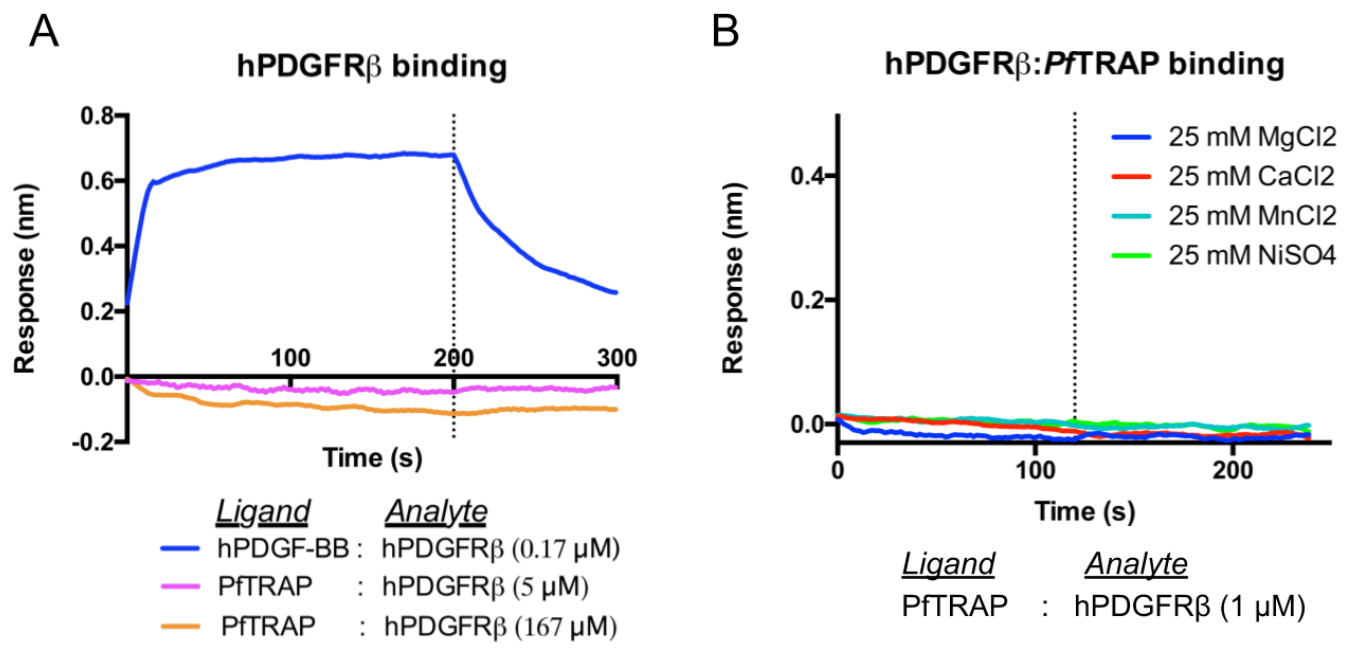

(A) Solutions containing recombinant biotinylated PfTRAP or hPDGF-BB (ligands) were used to derivatize streptavidin biosensors prior to incubating them in solutions containing recombinant hPDGFR $\beta$ (analyte) at the indicated concentrations for 200 s, subsequently incubating them in reference buffer for another 100s. (B) Experiments using biotinylated PfTRAP as ligand were performed in the presence of 25-mM concentrations of divalent cations, as indicated in the legend. Sensorgrams in each experiment were reference-subtracted using data from an analyte-free reference well. 


\section{Supplementary Figure 7: HEK293F cells express av-integrin.}

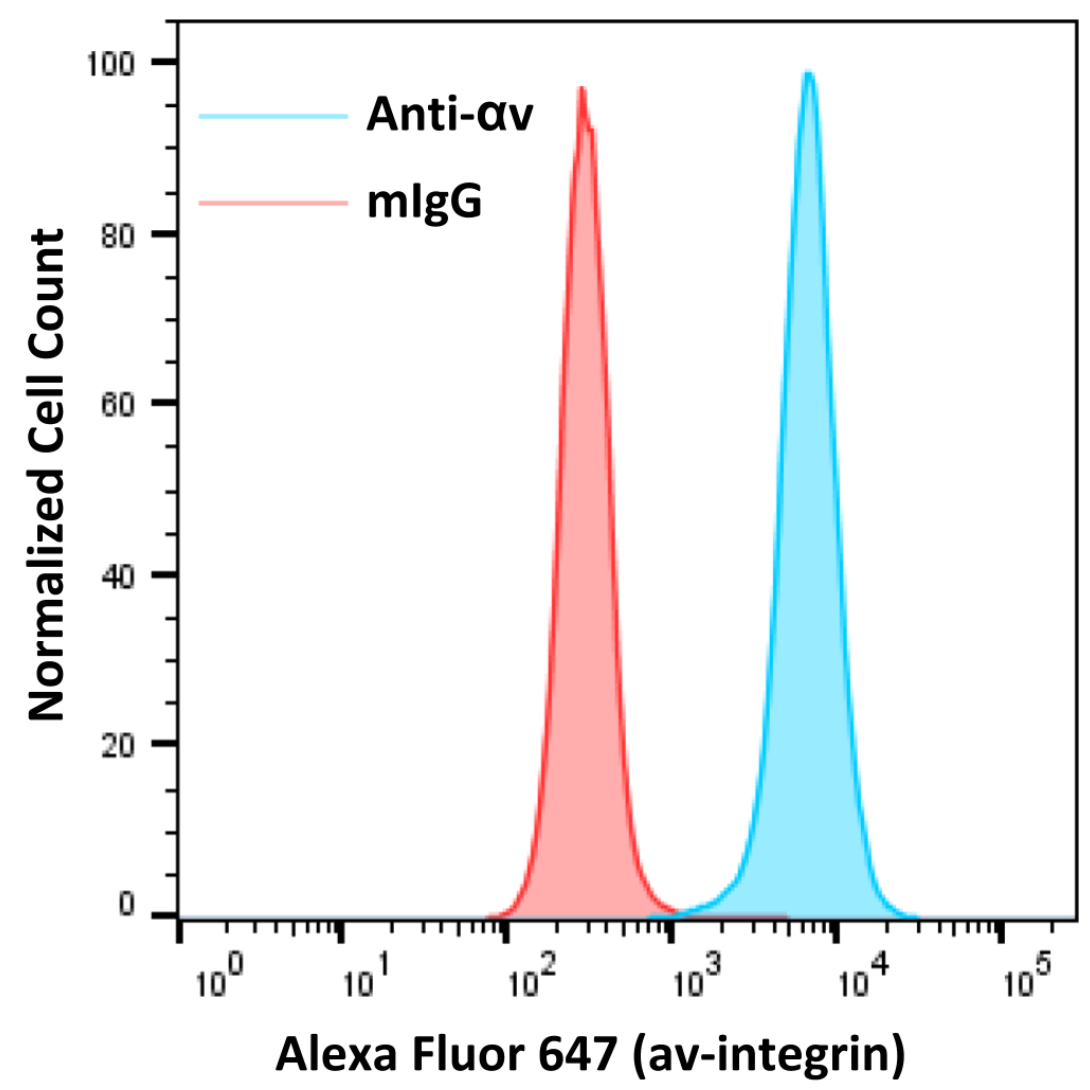

Untransfected HEK293F cells were incubated with $10 \mu \mathrm{g} / \mathrm{mL}$ anti-av-integrin antibody or mouse IgG (mlgG) before washing and staining with an anti-mouse Alexa Fluor 647 antibody. Cells incubated with the anti-av-integrin antibody were significantly brighter than the isotype control. 